\title{
Biomineralization of Calcium Phosphate Crystals Controlled by Protein-Protein Interactions
}

\author{
Elif Duman, ${ }^{\dagger, \ddagger}$ Ebru Şahin Kehribar, ${ }^{\dagger \neq}$ Recep Erdem Ahan, ${ }^{\dagger, \ddagger}$ Esra Yuca, ${ }^{\dagger, \ddagger}$, \\ and Urartu Özgür Şafak Şeker $*,+\ddagger 0$ \\ ${ }^{\dagger}$ Bilkent University UNAM - National Nanotechnology Research Center, Bilkent University, Ankara 06800, Turkey \\ ${ }^{\ddagger}$ Institute of Materials Science and Nanotechnology, Bilkent University, Ankara 06800, Turkey \\ ${ }^{\S}$ Department of Molecular Biology and Genetics, Yildiz Technical University, Istanbul 34210, Turkey
}

Supporting Information

\begin{abstract}
Hydroxyapatite (HAP) is the major biomineral of bone. Despite the large number of studies addressing HAP formation, a fundamental understanding of the critical roles of HAP-forming proteins in vitro is needed. Effects of two HAP-interacting proteins, osteocalcin (OCN) and osteopontin (OPN), on HAP formation was investigated via in vitro biomineralization experiments, and their outcomes on the crystal structure of calcium phosphate $(\mathrm{CaP})$ was revealed. Our data suggest that OCN concentration is negatively correlated with crystal formation rate and crystal size, yet the presence of OCN leads to a more ordered HAP crystal formation. On the other hand, OPN protein promotes faster formation of $\mathrm{CaP}$ crystals

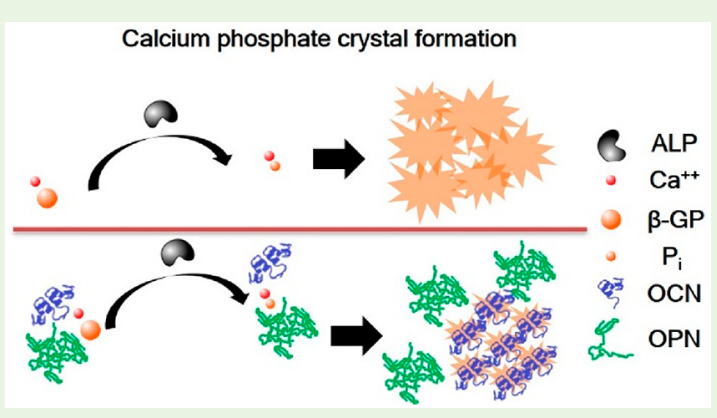
potentially working as a growth site for mineral formation, and it decreases the Ca:P ratio. This effect results in a shift from HAP-type minerals to less ordered crystals. The crystal size, shape, and Ca:P ratio can be tuned to design improved mammalian hard tissue environment-mimicking matrices by taking advantage of the OCN and OPN proteins on crystal formation. We believe our current findings will lead to innovative approaches for bone biomineralization in regenerative medicine.
\end{abstract}

KEYWORDS: biomineralization, hydroxyapatite crystals, protein-protein interaction

\section{INTRODUCTION}

Although hard tissues in the body are difficult to injure, the intrinsic healing capacity of these tissues is highly limited. ${ }^{1}$ In addition, several diseases can affect homeostasis of bone and teeth, such as bone cancer, osteoporosis, and dental pulp infections. $^{2-4}$ Commercial bone substitutes and dental prostheses for fracture healing and disease treatment are available. ${ }^{5,6}$ However, the properties of these materials need to be enhanced in order to provide better osteointegration while controlling the bone regeneration rate and preventing ectopic bone formation. ${ }^{7,8}$

Among synthetic bone substitutes, hydroxyapatite (HAP) grafts are one of the best in terms of their bioinertness and osteointegration capability. ${ }^{9-13}$ There are several methods for HAP synthesis; among them, wet chemical synthesis and hightemperature synthesis are the most studied routes. ${ }^{9}$ Despite their straightforward protocol, the methods suffer from many limiting factors. For example, wet chemical synthesis is the most promising method; however, precise control of crystallinity is not possible, which yields a low number of ordered crystals and high-impurity content. In addition, aging of crystals can take too long, which makes the process time consuming. ${ }^{9}$ High-temperature synthesis of HAP can be a better alternative to wet synthesis in terms of a more pure phase composition and higher crystallinity, but it requires a high amount of energy to heat the sample up to $2000^{\circ} \mathrm{C} .{ }^{9}$

Several organisms including mammalians can synthesize HAP crystals and other mineral forms. ${ }^{14}$ Organisms perform mineral synthesis with tight control mechanisms to provide high crystallinity and shape uniformity. Proteins, enzymes, and even small ions take part in this process. ${ }^{15-21}$ These components possess important roles in hard tissue development, bone remodeling, and bone regeneration. ${ }^{18,21-23}$ Mimicking biological mineral formation has potential as a promising route for HAP synthesis, as the physiological conditions such as $\mathrm{pH}$ and temperature can be easily adapted to the in vitro environment. Synthesized HAP molecules can be better adapted to the host tissue environment by biomimetic mineral formation. ${ }^{23-26}$

The nucleation and growth of HAP crystals are controlled by the proteins found in the extracellular matrix (ECM) in hard tissues. ${ }^{27}$ The organic part of the ECM is composed of collagen and noncollagenous proteins (NCPs). The main organic component of bone ECM is collagen I, which ensures growth of the crystals in a parallel orientation. However, many

Received: May 9, 2019

Accepted: July 9, 2019

Published: July 9, 2019 


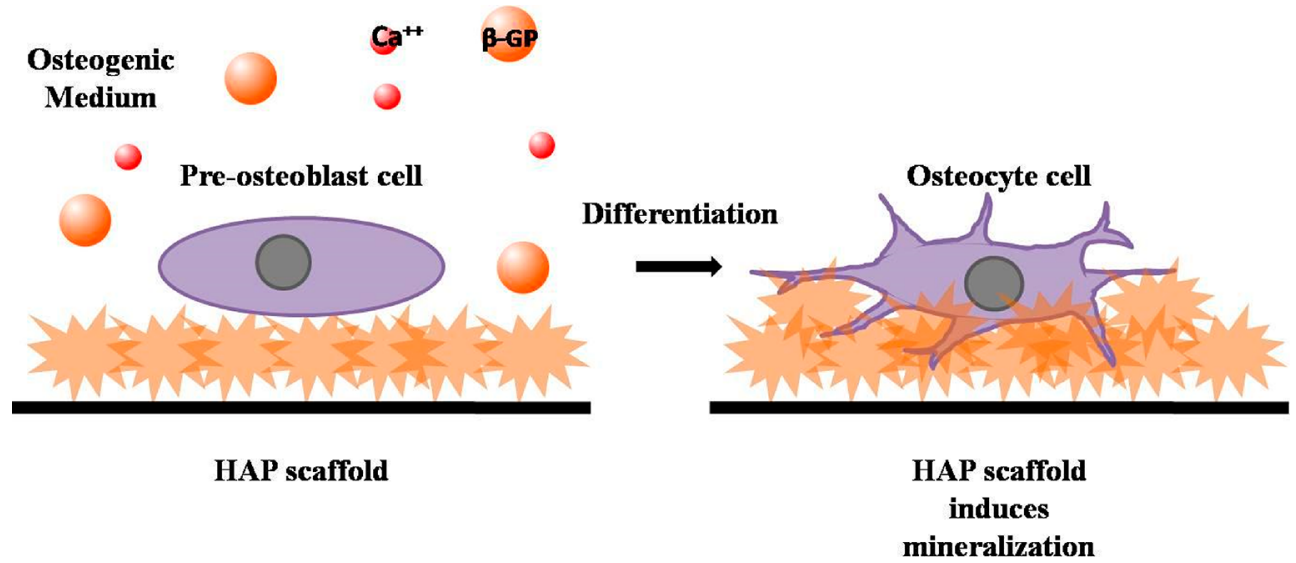

Figure 1. Graphical illustration depicting the effect of size/shape/CaP ratio controlled HAP scaffold on differentiation of osteoblast cells and induction of mineralization. In the presence of $\mathrm{Ca}$ ions and organic phosphate source, pre-osteoblasts can differentiate into osteocyte cells and deposit inorganic matrix. HAP scaffold hastens mineral deposition and propagate osteoblast differentiation.

other tissues, such as skin, cornea, blood vessels and tendons, also contain collagen I but are not mineralized. Collagen I is identified as a scaffold for mineralization, yet, NCPs present in ECM environment play important roles in controlling size, shape, and uniformity of crystals, in inhibition of mineralization, or in controlling crystal growth. ${ }^{28} \mathrm{OCN}$ and OPN are the most abundant NCPs. ${ }^{29,30} \mathrm{OCN}$ and OPN are both inhibitors of mineralization, but OPN also acts as a nucleator when it is cross-linked to the gap regions of the collagen fibers. ${ }^{31-34}$ Therefore, OCN and OPN are the most suitable candidates to study HAP formation in vitro.

Purification of proteins from bone tissue is a laborious work to study the interaction of these proteins in vitro. In addition, purification of the proteins may alter the secondary structure and functionality of the proteins since harsh conditions are applied during the extraction. ${ }^{35}$ On the other hand, bacterial platforms are easy to handle for production and purification of recombinant proteins. ${ }^{36-40}$ Several bone-related proteins are successfully produced and purified in these platforms, and they were investigated for their biomineralization activities. ${ }^{41-49}$

In this study, in vitro biomineralization of calcium phosphate (CaP) crystals was controlled in a truly biomimetic system composed of ALP, OCN, and OPN, which are the main components of bone ECM. While ALP is enough for mineral formation, the reaction rate, size, and shape of the crystals were affected by the presence of OCN and OPN. Controlled HAP growth will improve construction of mammalian hard tissue environment-mimicking matrices and tissue scaffolds in order to provide bone healing at the fracture site. These matrices will be suitable candidates to host hMSCs and pre-osteoblast cells. Fine-tuning/manipulation of OCN-OPN concentrations and ratio can create a valuable platform to control biomineralization in bone regeneration and tissue repair (Figure 1).

\section{EXPERIMENTAL SECTION}

Plasmid Construction. To express ALP, OCN, and OPN proteins in Escherichia coli BL21 (DE3), coding sequences were cloned in expression vectors. ALP coding gene phoA is found in most organisms with a universal function, conversion of organic phosphate into inorganic phosphate. ${ }^{18,50-54}$ Therefore, E. coli ALP was amplified by the primers listed in Table S3 from E. coli K12 MG1655 genome. pET22b $(+)$ vector was modified to add a polyhistidine tag coding sequence to the $5^{\prime}$ of the MCS after the pelB periplasmic space localization signal coding sequence. The modified plasmid was restriction digested with BamHI-HF (NEB R3101S) and XhoI (NEB
R0146S) in order to form 5472 bp linear vector. The phoA gene was double digested with BamHI and XhoI in order to form a $1356 \mathrm{bp}$ insert. Ligation by T4 ligase (NEB M0202S) was performed by using a 1:3 insert to vector molar ratio. The assembly product was transformed into a chemically competent E. coli DH5 $\alpha$ bacteria. Selected positive clones containing the $p h o A$ gene were sequenced, and phosphatase activity assay was performed for verification (Figures S1 and S4).

Human OCN and OPN coding sequence was codon optimized to E. coli $\mathrm{K}-12$ by using the IDT codon optimization tool (http://eu. idtdna.com/CodonOpt). Signal sequences were removed, and synthetic OCN and OPN genes were synthesized by Genscript Company. Nucleic acid and amino acid sequences of recombinant OCN and OPN are shown in Tables S1 and S2.

The synthetic OCN gene was cloned into a pGEX-6P1 vector using the Gibson assembly method with an addition of TEV protease cleavage site at $5^{\prime}$ of OCN for cleavage of the GST fusion protein, whose gene sequence is located at $5^{\prime}$ of MCS of the plasmid, after expression and 6xHis-tag at $3^{\prime}$ for purification by cobalt resin. The synthetic OCN gene was amplified by the primers listed in Table S3. A pGEX-6P1 vector was double digested with BamHI-HF (NEB R3136S) and EcoRI-HF (NEB R3101S) to form a 4999 bp linear vector. Digestion was verified by agarose gel electrophoresis. Gibson assembly was performed by using an equimolar ratio of insert and vector according to the protocol used elsewhere. ${ }^{55}$ The assembly product was transformed into chemically competent $E$. coli DH5 $\alpha$ bacteria. Selected positive clones containing the synthetic OCN gene product (273 bp) was sequence verified (Figure S2).

A synthetic OPN gene was cloned into a pET22b(+) vector, which contains a $6 \mathrm{X}$-His tag before stop codon, by ligation. A synthetic OPN gene was amplified by the primers listed in Table S3. The pET22b $(+)$ vector and OPN gene were double digested with NotI-HF (NEB R3189S) and XhoI(NEB R0146S) to form a 5492 bp linear vector and $855 \mathrm{bp}$ insert, respectively. Digestion was verified by agarose gel electrophoresis (data not shown). After the ligation step, the assembly product was transformed into chemically competent E. coli DH5 $\alpha$ bacteria. One of the positive clones containing the synthetic OPN gene product ( $855 \mathrm{bp}$ ) was sequence verified (Figure S3).

Recombinant Protein Expression. Sequence verified plasmids containing ALP, OCN, and OPN genes were transformed into chemically competent E. coli BL21 (DE3) bacteria for expression. ALP and OPN are under the control of isopropyl $\beta$-D-1thiogalactopyranoside (IPTG) inducible T7 promoter, whereas OCN expression is controlled by IPTG inducible tac promoter. Overnight culture of transformed bacteria were diluted in LuriaBertani (LB) broth in a $1: 50$ ratio, inoculated in a $37{ }^{\circ} \mathrm{C} 200 \mathrm{rpm}$ incubator until bacteria reach the pre-log phase $\left(\mathrm{OD}_{600}=0.5-0.6\right)$ and protein expression was induced by $1 \mathrm{mM}$ IPTG (Amresco 048710G). ALP was induced for $4 \mathrm{~h}$ at $37^{\circ} \mathrm{C}$, and $\mathrm{OCN}$ and OPN were 
induced for $8 \mathrm{~h}$ at $30^{\circ} \mathrm{C}$. The bacteria were centrifuged at $8000 \mathrm{RCF}$ following inductions, and cell pellets were stored at $-80^{\circ} \mathrm{C}$ until the purification step.

Purification of Recombinant Proteins by Cobalt Resin for Small-Scale Purification. For $25 \mathrm{~mL}$ of culture, the cell pellet was resuspended in $1 \mathrm{~mL}$ of lysis buffer $\left(50 \mathrm{mM} \mathrm{Na} 2 \mathrm{HPO}_{4} \cdot 2 \mathrm{H}_{2} \mathrm{O}\right.$ (Merck 106342), $300 \mathrm{mM} \mathrm{NaCl}$ (Merck 1.06404-1KG), $10 \mathrm{mM}$ imidazole (VWR 0527-50G)), $1 \mathrm{mg} / \mathrm{mL}$ lysozyme (Sigma L6876-10G) and 1 $\mathrm{mM}$ phenylmethanesulfonylfluoride (PMSF) (Amresco m145-5G). Bacteria were allowed to lyse for $1 \mathrm{~h}$ on ice and then centrifuged for $25 \mathrm{~min}$ at $18000 \mathrm{RCF}$. $200 \mu \mathrm{L}$ of cobalt resin (Thermo Scientific 89964-10 ML) was washed twice with $1 \mathrm{~mL}$ of wash buffer $(50 \mathrm{mM}$ $\mathrm{Na}_{2} \mathrm{HPO}_{4}, 300 \mathrm{mM} \mathrm{NaCl}$, and $10 \mathrm{mM}$ imidazole) to remove EtOH, and the lysis supernatant was added to the cobalt resin. Binding of His-tagged proteins to cobalt resin was performed at room temperature in an end-over-end rotator for $2 \mathrm{~h}$. The resin was washed twice with $1 \mathrm{~mL}$ of wash buffer, and proteins were eluted in $100 \mu \mathrm{L}$ of elution buffer $\left(50 \mathrm{mM} \mathrm{Na} \mathrm{HPO}_{4}, 300 \mathrm{mM} \mathrm{NaCl}\right.$, and 150 $\mathrm{mM}$ imidazole) for 5 times. Purification of proteins was verified by sodium dodecyl sulfate polyacrylamide gel electrophoresis (SDSPAGE) and Western blotting using antibody against 6x His-tag.

Purification of Recombinant Proteins by Nickel Column for Large-Scale Purification. For $150 \mathrm{~mL}$ of culture, the cell pellet was resuspended in $5 \mathrm{~mL}$ of lysis buffer $\left(50 \mathrm{mM} \mathrm{Na}_{2} \mathrm{HPO}_{4}, 300 \mathrm{mM}\right.$ $\mathrm{NaCl}$, and $20 \mathrm{mM}$ Imidazole), $5 \mathrm{mg} / \mathrm{mL}$ lysozyme, and $5 \mathrm{mM}$ PMSF. Bacteria were allowed to lyse for $1 \mathrm{~h}$ on ice and then centrifuged for $25 \mathrm{~min}$ at $18,000 \mathrm{RCF}$. The supernatant was filtered through a 0.45 $\mu \mathrm{m}$ PTFE membrane filter (Isolab). The proteins were loaded to a nickel column in an preparative high-pressure liquid chromatography (Prep-HPLC, Agilent) device with binding buffer $\left(50 \mathrm{mM} \mathrm{Na}_{2} \mathrm{HPO}_{4}\right.$, $300 \mathrm{mM} \mathrm{NaCl}$, and $20 \mathrm{mM}$ imidazole) and eluted to a fraction collector in $2 \mathrm{~mL}$ aliquots with elution buffer $\left(50 \mathrm{mM} \mathrm{Na}_{2} \mathrm{HPO}_{4}, 300\right.$ $\mathrm{mM} \mathrm{NaCl}$, and $500 \mathrm{mM}$ imidazole). HPLC reaction conditions were as following: $35 \mathrm{~min}$ binding buffer, 10 min elution buffer with $1 \mathrm{~mL} /$ min flow rate, and 5 bar maximum pressure limit. Purification of proteins was verified by SDS-PAGE and Western blotting.

Removal of GST Tag from OCN. Purified GST-OCN ( $35 \mathrm{kDa})$ was concentrated and buffer exchanged to $25 \mathrm{mM}$ Tris ( $\mathrm{pH}$ 7.4) with a $10 \mathrm{kDa}$ cutoff filter unit. A $1-2 \mu \mathrm{L}$ of TEV protease (Sigma T4455) was used to cut the GST tag from the GST-OCN protein purified from $25 \mathrm{~mL}$ of culture. The GST cleavage reaction was carried out in $25 \mathrm{mM}$ Tris ( $\mathrm{pH} 7.4$ ) with $20 \times$ reaction buffer (1 M Tris-HCl (Sigma T5941-500G) (pH 8.0), 10 mM EDTA (Sigma E5134-500G), and 1 $\mathrm{mM}$ DTT (Invitrogen P2NY00147) at $30{ }^{\circ} \mathrm{C}$ for $5 \mathrm{~h}$ or at room temperature for $24 \mathrm{~h}$ (Figure S5B). $20 \mu \mathrm{L}$ of cleavage reaction mixture was taken for SDS-PAGE analysis. The reaction mixture buffer was exchanged to $1 \times$ PBS (prepared from 10× PBS stock containing 1.37 $\mathrm{M} \mathrm{NaCl}, 26.8 \mathrm{mM} \mathrm{KCl}$ (Merck 1.04936-1KG), $0.1 \mathrm{M} \mathrm{Na}_{2} \mathrm{HPO}_{4}, 17.6$ $\mathrm{mM} \mathrm{K}_{2} \mathrm{HPO}_{4}$ (Merck $1.05104-1 \mathrm{KG}$ ), $\mathrm{pH}=7.4$ by dilution with $\mathrm{ddH}_{2} \mathrm{O}$ ) with $3 \mathrm{kDa}$ cutoff filter unit (Pierce 88515). GST bind resin (Novagen 70-541-3-10 ML) was used to separate GST from OCN after a TEV cut. One $\mathrm{mL}$ of GST resin was washed twice with $2.5 \mathrm{~mL}$ $1 \times$ PBS to remove EtOH. The TEV reaction mix was diluted in $1 \times$ PBS to $2.5 \mathrm{~mL}$ and added onto the GST bind resin. The binding step was performed at room temperature for $2 \mathrm{~h}$ in an end-over-end rotator. The unbound fragment was collected, concentrated, and buffer exchanged to $25 \mathrm{mM}$ Tris ( $\mathrm{pH} 7.4$ ) with a $3 \mathrm{kDa}$ cutoff filter unit. The resin was washed twice with $2.5 \mathrm{~mL} 1 \times$ PBS, and GST was eluted at least twice in $250 \mu \mathrm{L}$ GST elution buffer $(50 \mathrm{mM}$ Tris- $\mathrm{HCl}$, $10 \mathrm{mM}$ L-glutathione, reduced (Cayman Chemical 10077461-10G), $\mathrm{pH}=8.0) .20 \mu \mathrm{L}$ of unbound, 2 wash and 2 elution samples was collected for SDS-PAGE analysis (Figure S5C).

SDS-PAGE and Coomassie Blue Staining. $20 \mu \mathrm{L}$ of protein was premixed with $4 \mu \mathrm{L}$ of $6 \times$ Laemmli sample buffer (1.2 g SDS, $6 \mathrm{mg}$ bromophenol blue (Amresco 0449-25G), $4.7 \mathrm{~mL}$ of glycerol (VWR 0854-1L), $1.2 \mathrm{~mL}$ Tris (0.5M, pH 6.8), $2.1 \mathrm{~mL}$ of $\left.\mathrm{ddH}_{2} \mathrm{O}\right)$ and denatured at $95{ }^{\circ} \mathrm{C}$ for $5 \mathrm{~min}$. ALP and GST-OCN and OPN samples were loaded in $12 \%$ SDS-polyacrylamide gel, and OCN samples were loaded in 15\% SDS-polyacrylamide gel. SDS-PAGE was performed at $120 \mathrm{~V}$ for $10 \mathrm{~min}$ for stacking and $190 \mathrm{~V}$ for 50-60 min for resolving.
The gel was either stained with Coomassie Brilliant Blue (CBB) solution (45\% methanol (Sigma 34885-2.5L), 10\% acetic acid (Sigma 27225-2.5L), $3 \mathrm{~g} / \mathrm{L}$ Brilliant Blue G (Sigma 27815-25G-F)) and destained in destaining buffer (10\% acetic acid, 30\% methanol) or used for transferring proteins into a polyvinylidenedifluoride (PVDF) transfer membrane (Thermo Scientific 88520) for Western blotting.

Western Blotting. After SDS-PAGE, the proteins in the gel were re-transferred into a PVDF membrane with Transblot Turbo Transfer System (Biorad). For high MW proteins, transfer was performed at 25 $\mathrm{kV}, 1.3 \mathrm{~A}$ for $7 \mathrm{~min}$, and for low MW proteins, transfer was performed at $25 \mathrm{kV}, 1.3 \mathrm{~A}$ for $5 \mathrm{~min}$. The membrane was blocked in $3 \%$ milk powder in $1 \times$ TBS-T (Prepared from 10 TBS stock containing $24.2 \mathrm{~g}$ of Tris-base (Merck 1.08387-2.5KG), $80 \mathrm{~g}$ of $\mathrm{NaCl}$ pH 7.6 in $1 \mathrm{~L}$ of $\mathrm{ddH}_{2} \mathrm{O} .100 \mathrm{~mL} 10 \times$ TBS was diluted in $900 \mathrm{~mL}$ of $\mathrm{ddH}_{2} \mathrm{O}$, and 10 $\mathrm{mL}$ of $10 \%$ Tween-20 (Thermo Scientific $85114-250 \mathrm{ML}$ ) was added to prepare $1 \times \mathrm{TBS}-\mathrm{T}$ for $1 \mathrm{~h}$ with agitation. Then, it was transferred into the primary antibody solution (1:10000 dilution of mouse anti6X-His Tag mAb (HIS.H8) (PTGLAB 66005-1-1G-0.15 ML) in 5\% milk powder in $1 \times \mathrm{TBS}-\mathrm{T}$ ) and incubated for $1 \mathrm{~h}$ at room temperature with agitation. The membrane was washed with $1 \times$ TBS$\mathrm{T} 3$ times for 5,15 , and $5 \mathrm{~min}$ each. Then, the membrane was incubated in secondary antibody solution (1:10,000 dilution of goat anti-mouse IgG H\&L (HRP) (Abcam ab6789-1 MG) in 5\% milk powder in $1 \times \mathrm{TBS}-\mathrm{T}$ ) for $1 \mathrm{~h}$ at room temperature with agitation. The membrane was washed with $1 \times$ TBS-T 3 times for 5,15 , and 5 min each. The HRP-conjugated secondary antibody was detected by ECL substrate (Biorad 170-5060-200 ML) after 1 min incubation in the dark and imaged using a ChemiDoc MP imaging system (Biorad).

Protein Quantitation. All proteins were concentrated and buffer exchanged to $25 \mathrm{mM}$ Tris ( $\mathrm{pH} 7.4$ ) before quantitation. Seven serial dilutions of $2 \mathrm{mg} / \mathrm{mL}$ BSA (Pierce 23209) were prepared for standard curve preparation according to manufacturer's protocol (Pierce BCA Protein Assay Kit 23225). $9 \mu \mathrm{L}$ of BSA or protein of interest and 260 $\mu \mathrm{L}$ of working reagent was used for reaction in triplicates. Working reagent was freshly prepared from reagent $A$ and reagent $B$ in a 50:1 ratio. The reaction was performed at $37^{\circ} \mathrm{C}$ for $30 \mathrm{~min}$ and read in a SpectraMax M5 spectrophotometer (Molecular Devices) at $562 \mathrm{~nm}$ absorbance. The concentrations of proteins were calculated by standard BCA assay protocol in Softmax Pro software.

ALP Unit Enzyme Concentration. Purified ALP was concentrated and buffer exchanged to $25 \mathrm{mM}$ Tris ( $\mathrm{pH} 7.4)$ using a $30 \mathrm{kDa}$ cutoff filter unit (Pierce 88529). A standard curve was prepared with 7 serial dilutions of $140 \mu \mathrm{M}$ pNP (Fluka 35836), and 7 serial dilutions of ALP were performed and mixed with $0.5 \mathrm{mM}$ pNPP (Sigma 20-106 EMD Millipore) in 1:1 ratio. Each reaction was performed in triplicate. The plate was incubated at $37^{\circ} \mathrm{C}$ for $5 \mathrm{~min}$, and absorbance at $405 \mathrm{~nm}$ was measured. pNP concentration formed in each dilution was calculated based on the pNP standard curve. Reaction velocity ( $\mathrm{pNP} / \mathrm{min}$ ) was calculated, and $1 \mathrm{U}$ enzyme was designated to the concentration which forms $1 \mu \mathrm{M} \mathrm{pNP} / \mathrm{min}$ (data not shown).

ALP Enzymatic Activity. Five serial dilutions of $4 \mathrm{mM}$ pNPP substrate were performed in the pNPP reaction buffer $(0.1 \mathrm{M}$ lysine (Amresco 0167-1 KG), $1 \mathrm{mM} \mathrm{MgCl} 2$ (Sigma M4880-100 G), and 1 $\mathrm{mM} \mathrm{ZnCl}$ (NEB 7646-85-7)). A final concentration of $1 \mathrm{U}$ ALP in $25 \mathrm{mM}$ Tris was used for each reaction with or without the addition of OCN and OPN proteins. Each reaction was performed in triplicate. The plate was incubated at $37{ }^{\circ} \mathrm{C}$ for $10 \mathrm{~min}$, and absorbance at 405 $\mathrm{nm}$ was measured. pNP concentration was calculated for each dilution sample based on the pNP standard curve. Reaction velocity $(\mu \mathrm{M}$ $\mathrm{pNP} / \mathrm{min}$ ) was calculated, Michaelis-Menten graphics were drawn, and $K_{\mathrm{m}}(\mu \mathrm{M})$ and $v_{\max }(\mu \mathrm{M} / \mathrm{min})$ values were calculated by Graphpad Prism 6 software. Nonlinear regression curve fitting was performed to fit experimental data with maximum number of iterations (95\% confidence interval, R2 $>0.9$ for each group). Second-order polynomial smoothing and 4 number of neighbors averaging were applied to the curve of Michaelis-Menten graphs. Statistical significance of $K_{\mathrm{m}}, k_{\text {cat }}$ (data not shown), and $v_{\max }$ values were calculated by Two-Way ANOVA in Graphpad Prism 6 software.

Circular Dichroism (CD) Spectra Analysis. Secondary structures of OCN and OPN and the effect of calcium and phosphate on 
A.

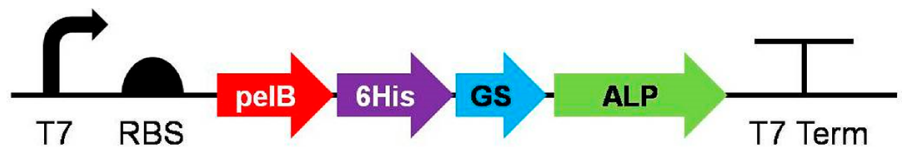

T7 Term
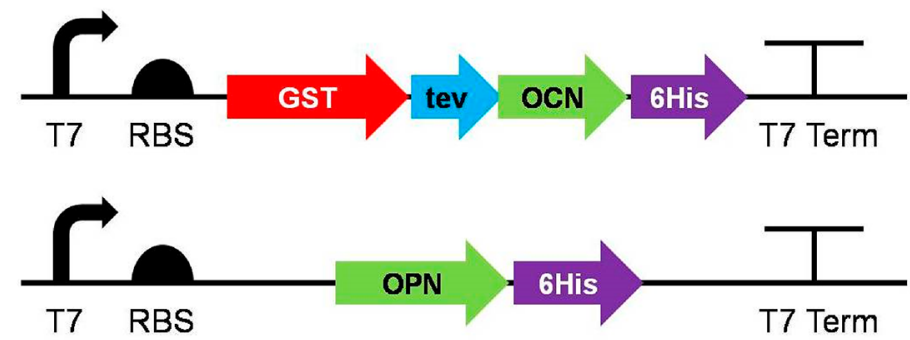

B.
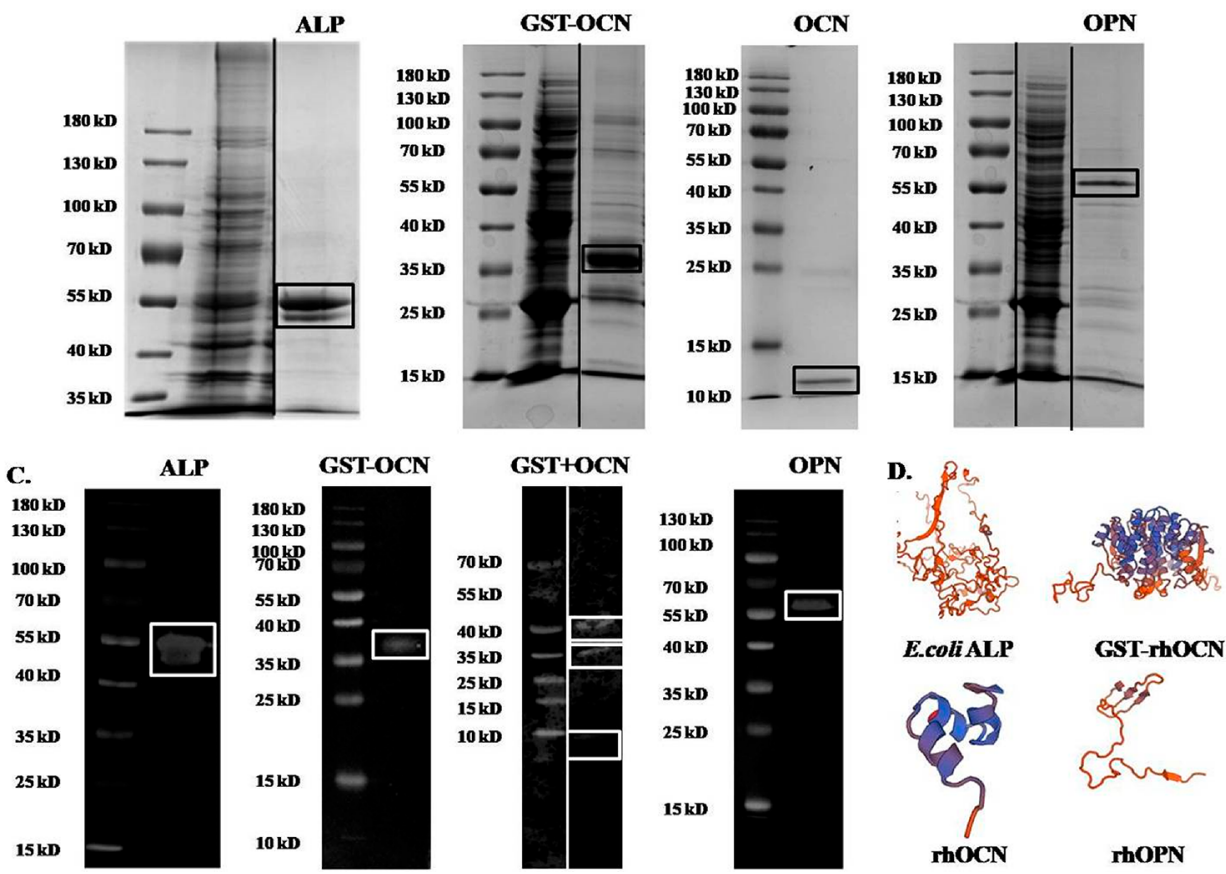

Figure 2. Genetic design, protein modeling, expression, and purification of ALP, GST-rhOCN, and rhOPN. (A) Genetic part designs of ALP, OCN, and OPN expression vectors. (B) Expression and purification of recombinant proteins. First lane is the ladder (NEB PageRuler) for each image, second lane is the cell lysate supernatant for ALP, GST-OCN, and OPN. Last lanes are purified proteins, and expected bands are shown in rectangles. Removal of the GST tag from OCN is shown in more detail in Figure S5. (C) Verification of protein purification by Western blot analysis using antibodies against the 6X-His tag. First lane is the ladder for each image, and the second lanes are ALP, GST-OCN, GST, and OCN after TEV protease cleavage and OPN, respectively. Expected bands are shown in rectangles. (D) Protein secondary structure models generated by ExPASy Online Tool by using codon optimized DNA sequences of each protein except bacterial ALP, which was not codon optimized.

their secondary structures were assessed by a CD spectra measurement device (Jasco J-815) at 25 and $37^{\circ} \mathrm{C}$ with 300 s delay time, 1 $\mathrm{mm}$ bandwidth. OCN and OPN proteins were buffered in $1 \mathrm{mM}$ Tris, and their interactions with calcium and phosphate were measured by addition of $1 \mathrm{M} \mathrm{CaCl}_{2}$ (Merck 1.02378-500 G), $\mathrm{Na}_{2} \mathrm{HPO}_{4}$, or $\beta$-GP (Calbiochem 35675-100 G) to a final concentration of $5 \mathrm{mM}$.

Biomineralization Assay. HAP formation capacity of ALP in the presence of varying concentrations OCN and OPN was analyzed. The protocol was adapted from previous work in the literature. ${ }^{56}$ Briefly, $2 \times$ biomineralization buffer (BB: $48 \mathrm{mM} \mathrm{CaCl} 2,28.8 \mathrm{mM} \beta$ glycerophosphate ( $\beta$-GP), $25 \mathrm{mM}$ Tris- $\mathrm{HCl} \mathrm{pH} 7.4)$ was prepared. $1 \times \mathrm{BB}, 1 \mathrm{mM} \mathrm{MgCl}, 5 \mathrm{U} \mathrm{ALP}$, and varying concentrations of $\mathrm{OCN}$ and OPN were mixed in 96-well plate wells. Light scattering measurement was performed for $1 \mathrm{~h}$ at $37^{\circ} \mathrm{C}$ to detect initial $\mathrm{CaP}$ formation. Then, the plate was incubated at $37^{\circ} \mathrm{C}$ for $24 \mathrm{~h}$ to prepare samples for SEM imaging, energy dispersive spectroscopy (EDS), and X-ray photoelectron spectroscopy (XPS) measurements. The reactions were performed in triplicate. Observable reaction rate values were calculated from the reaction curves. The slope of the first 30-40 min of mineral formation was designated as $k_{\text {observable. }}$

Scanning Electron Microscopy (SEM). $5 \mu \mathrm{L}$ of sample from the biomineralization assay plate was dropped onto a prewashed silicon wafer and incubated for $10 \mathrm{~min}$ at room temperature. The wafer was

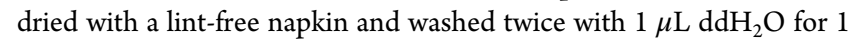
min. After drying, the wafer was kept in a vacuum desiccator until imaging. Before imaging, the wafer surface was coated with $5 \mathrm{~nm} \mathrm{Au} /$ Pd. The images were taken by an E-SEM microscope (FEI-Quanta 200 FEG). A representative image was shown in the figures for all groups. Crystal sizes from SEM images were measured by ImageJ Software. Statistical analysis of crystal size was performed by Graphpad Prism 6 software by unpaired $t$ test. The number of size measurements, the mean size, and standard error mean (SEM) values are indicated both in the results section and figure captions. EDS analysis was performed with the EDAX Genesis software attached to a SEM microscope. Operating conditions were the same for all measurements (accelerating voltage: $5 \mathrm{kV}$, spot size 3.0). 
A.

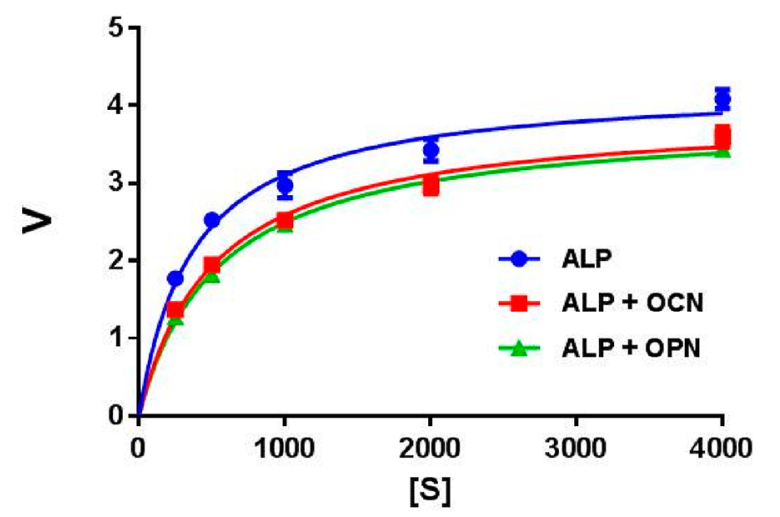

C.

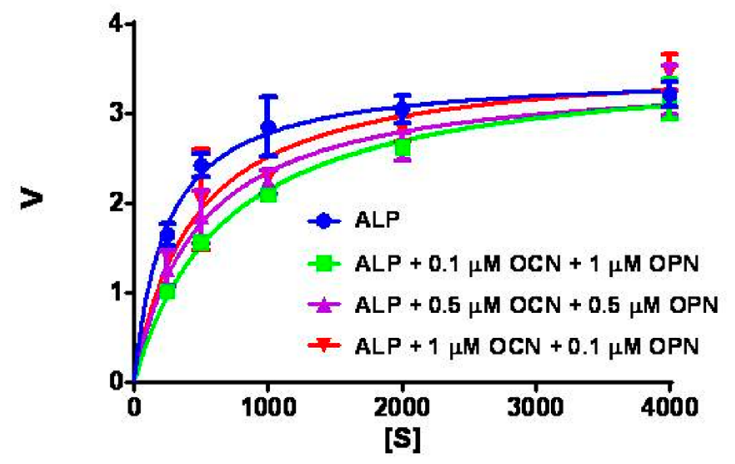

B.

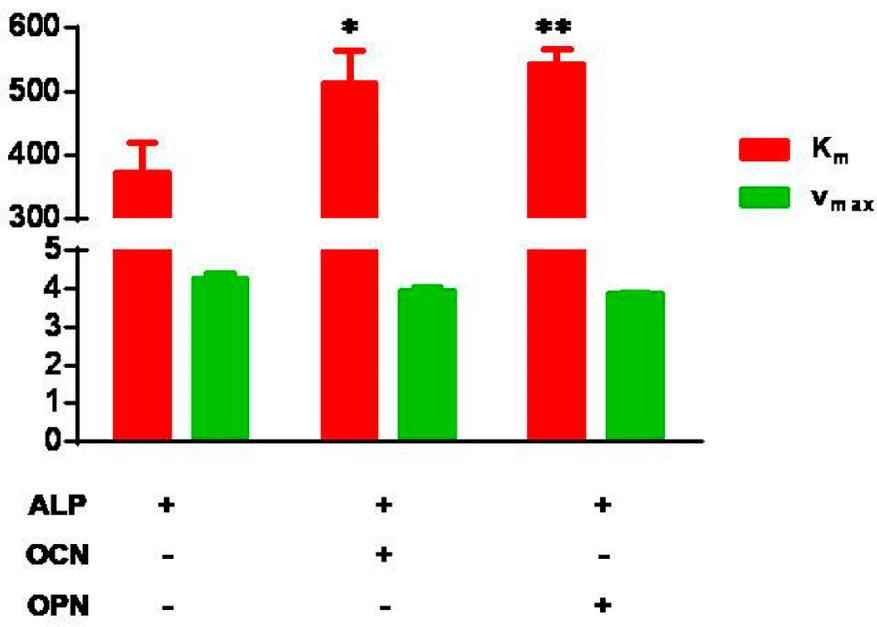

D.

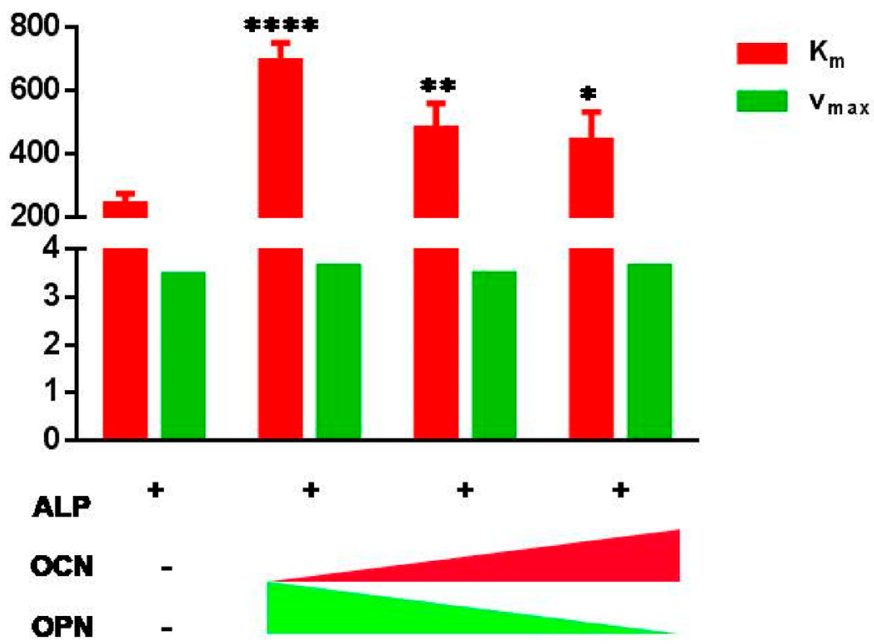

Figure 3. Characterization of ALP enzymatic activity in the presence of OCN and OPN. (A) ALP activity in the presence of OCN or OPN. (B) $K_{\mathrm{m}}$ $(\mu \mathrm{M})$, the reaction rate constant, increased in the presence of OCN and OPN. (C) ALP activity in the presence of varying concentrations of OCN and OPN. (D) $K_{\mathrm{m}}$ increased in the presence of varying concentrations of OCN and OPN. The $v_{\max }(\mu \mathrm{M} \mathrm{pNP} / \mathrm{min})$ is constant for all cases. The experiment was performed in triplicate. Nonlinear regression curve fitting was performed to fit experimental data on Michaelis-Menten curve (AC). Two-way ANOVA was performed to compare each group with the ALP only group (B-D). The $v_{\max }$ was not statistically significant, while $K_{\mathrm{m}}$ significantly increased for all groups.

X-ray photoelectron spectroscopy (XPS) analysis. Biomineralization assay plate was taken from $37^{\circ} \mathrm{C}$ at $24 \mathrm{~h}$, and the content of each well was transferred into a microcentrifuge tube. The sample was centrifuged at $8000 \mathrm{RCF}$ for $2 \mathrm{~min}$, and the supernatant was removed. $100 \mu \mathrm{L}$ of $\mathrm{pH} 10$ water $\left(10 \% \mathrm{NH}_{4} \mathrm{OH}\right)$ was added to each tube to stop the reaction, and and each tube was centrifuged at $8000 \mathrm{RCF}$ for $2 \mathrm{~min}$. Supernatant was removed, and the sample was washed with $100 \mu \mathrm{L}$ of EtOH. The sample was centrifuged at $8000 \mathrm{RCF}$ for $2 \mathrm{~min}$, supernatant was removed, and the sample was air-dried for 3-5 min. The samples were kept at room temperature in a desiccator until analysis. The elemental composition of samples was analyzed by XPS (Thermo Scientific K-Alpha spectrometer). The binding energy (BE) scale was adjusted based on the measurement of adventitious $\mathrm{C}$ $(284.6 \mathrm{eV})$. The survey scan was acquired with scan number 2 , and the high-resolution detailed scans of $\mathrm{Ca}(2 \mathrm{p}), \mathrm{P}(2 \mathrm{p}), \mathrm{O}(1 \mathrm{~s})$, and $\mathrm{C}(1 \mathrm{~s})$ were acquired with scan numbers $10-30$ based on the intensity of the signal. A $400 \mu \mathrm{m}$ spot size was chosen for each point, and all samples were scanned from 3 different points. An adjusted $\mathrm{Ca} / \mathrm{P}$ ratio was calculated based on the protocol described elsewhere. ${ }^{57}$ Statistical analysis of crystal size was performed by Graphpad Prism 6 Software by unpaired $t$ test.

\section{RESULTS AND DISCUSSION}

Cloning, Expression, and Purification of ALP, OCN, and OPN. ALP is a conserved enzyme, and it is found in different species, from mammalians to prokaryotes. Bacterial ALP has a structural homology with human ALP, and it has the same function of converting organophosphate into inorganic phosphate, which is the initial requirement of mineral formation. ${ }^{53}$ Therefore, phoA gene coding for bacterial ALP was amplified from the genomic DNA of the E. coli K-12 strain and cloned into the pET22b $(+)$ plasmid (Figure 2A). Commercial plasmid contains a $6 \mathrm{X}$ His-tag sequence at the $3^{\prime}$ end of the MCS, at the C-terminal of the protein. Protein purification and Western blot analysis of bacterial ALP with C terminal His tag using an anti-His tag antibody were not successful (data not shown). Consequently, the His tag sequence was moved to the $\mathrm{N}$-terminal of the ALP downstream of the periplasmic translocation signal pelB. Since pelB can localize ALP to the periplasmic space, the native periplasmic space localization signal of ALP was 

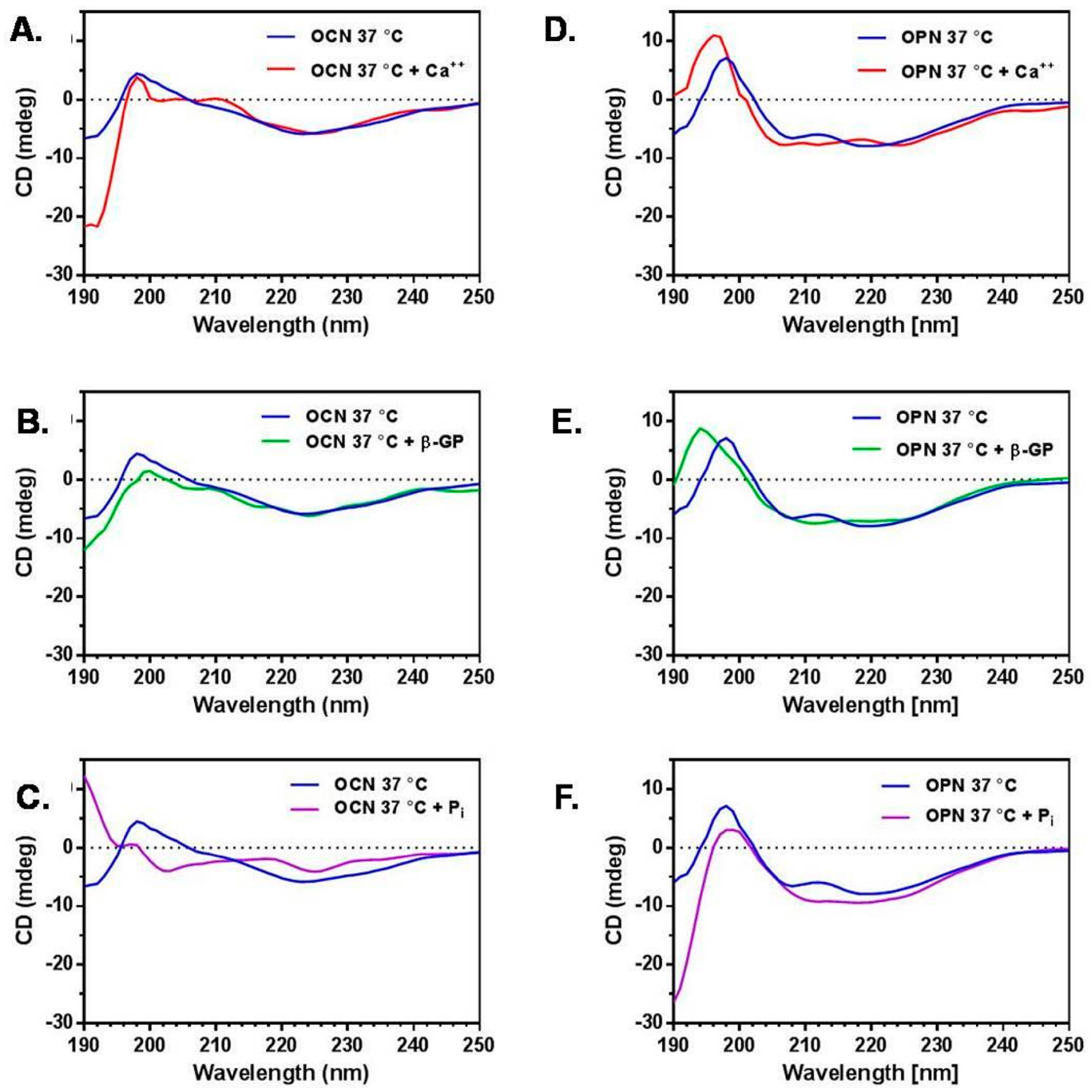

Figure 4. $\mathrm{CD}$ spectrum measurement for secondary structure analysis of $\mathrm{OCN}$ and $\mathrm{OPN}$ in the presence of biomineralization molecules. (A) OCN helical and anti-parallel structures were increased following the addition of $\mathrm{Ca}^{2+}$. (B, C) The $\alpha$-helical structure of OCN is disrupted in the presence of inorganic phosphate, not organic phosphate. (D) Secondary structure of OPN following the addition of $\mathrm{Ca}^{2+}$ is largely conserved. (E, F) OPN becomes more compact in the presence of inorganic phosphate, not the organic phosphate.

removed (Figure 2A). The expression of ALP was induced by IPTG in a BL21 strain, and ALP was extracted by standard lysis protocol to obtain both cytoplasmic and periplasmic fractions. Prior to purification, the overexpression of ALP was detected in cloned bacteria after a $4 \mathrm{~h}$ induction with $1 \mathrm{mM}$ IPTG compared to control bacteria by PNPP phosphatase assay (Figure S4). Then, ALP was purified by immobilized metal affinity chromatography (IMAC). Two fragments that have approximately $50 \mathrm{kDa}$ molecular weights were detected both in SDS-PAGE followed by Coomassie blue staining and in Western blotting using antibodies against the polyhistidine tag (Figure 2B,C). The smaller fragment might correspond to the periplasmic space-localized ALP, and the larger one could correspond to the cytoplasmic fraction since the 22 amino acid long pelB signal fragment is cleaved after localization. ${ }^{58}$

A synthetic OCN gene was amplified by PCR and cloned into the pET22b(+) plasmid, which contains $6 \mathrm{X}$-His tag at the $3^{\prime}$ end of MCS. OCN is a $\sim 10 \mathrm{kDa}$ small soluble protein, and it could not be detected in Western blot using the 6X-His antibody (data not shown). Therefore, it was cloned into another vector, pGEX-6P1, which contains the GST gene prior to MCS. GST is a highly soluble and easily producible protein, and it is generally used to improve the efficiency of recombinant protein production and solubility of the protein. ${ }^{46}$ A TEV protease recognition site was added between GST and OCN to cleave the GST tag after purification. A $6 \mathrm{X}-\mathrm{His}$ tag was added to the C-terminal of the protein for IMAC purification (Figure 2A). First, the GST-OCN fusion protein was expressed in E. coli BL21 (DE3) bacteria. The bacteria were lysed, and fusion protein was purified with the IMAC method (Figure 2B,C). Then, the GST-OCN fusion protein was cleaved with TEV protease (Figure S5B and Figure 2D), and GST was removed with the GST binding resin (Figure 2B and Figure S5C).

Compared to OCN, OPN is a large $\sim 33 \mathrm{kDa}$ soluble protein, and it can be produced in bacteria recombinantly without any solubility-enhancing tag. A synthetic OPN gene was amplified by PCR and cloned into the pET22b(+) plasmid. A 6X-His tag was placed at the $3^{\prime}$ end of the MCS of commercial plasmid, and it was therefore added to the $\mathrm{C}$ terminal of protein (Figure 2A). OPN was expressed in the $E$. coli BL21 (DE3) strain using IPTG induction. Following 
IMAC purification, a clear band around $50 \mathrm{kDa}$ was observed after SDS-PAGE Coomassie blue staining and Western blot analysis using antibodies against 6X-His tag (Figure 2B,C). Because OPN is a negatively charged protein, it was observed at a higher molecular weight than expected $(\sim 33 \mathrm{kDa})$. Detection of OPN as an approximately $50 \mathrm{kDa}$ fragment is consistent with the literature. ${ }^{33}$

OCN and OPN Change the Enzyme Activity of ALP by Competitive Binding. OCN and OPN affect the biomineralization process because their negatively charged residues provide binding sites for calcium phosphate crystals. However, it is not known whether they change the enzymatic activity of ALP or not. To investigate, the Michaelis-Menten kinetic analysis was performed in the presence of ALP, OCN, and/or OPN. Although $v_{\max }$ did not change, $K_{\mathrm{m}}$ increased in the presence of OCN and/or OPN (Figure 3B,D). When the substrate concentration was increased, the chance of OCN and OPN to reduce enzyme activity was decreased due to the high abundance of substrate. However, a higher concentration of substrate was required to reach the enzyme to half-maximum velocity, which means OCN and OPN increased $K_{\mathrm{m}}$, indicating a competitive binding. In the presence of $1 \mathrm{U}$ ALP and $0.5 \mu \mathrm{M}$ OCN or OPN, $K_{\mathrm{m}}$ increased 1.4- and 1.5-fold, respectively (Figure 3A,B).The data suggest that OCN and OPN bind to organophosphate, decreasing its probability of interaction with ALP. Moreover, OPN was more effective in competitive inhibition of ALP than OCN. In the presence of $1 \mathrm{U}$ ALP and varying concentrations of $\mathrm{OCN}$ and $\mathrm{OPN}$, the same effect can be observed (Figure 3C,D). In the presence of $1 \mu \mathrm{M}$ OCN and $0.1 \mu \mathrm{M}$ OPN, $K_{\mathrm{m}}$ increased 1.8 -fold. When the OCN concentration was decreased to $0.5 \mu \mathrm{M}$ and the OPN concentration was increased to $0.5 \mu \mathrm{M}, K_{\mathrm{m}}$ increased 2-fold. When the OCN concentration was further decreased to 0.1 $\mu \mathrm{M}$ and the OPN concentration was increased to $1 \mu \mathrm{M}, K_{\mathrm{m}}$ increased more dramatically (2.9-fold), supporting the idea of OPN being more effective in the competitive binding to organophosphate. In all cases, $v_{\max }$ did not change significantly, suggesting that ALP conformation and the binding of organophosphate to the active site of ALP were not affected by the presence of OCN and OPN.

Binding of OCN and OPN to Calcium and Phosphate. The CD spectra of OCN and OPN were obtained to analyze the secondary structures of OCN and OPN. Moreover, the change in the secondary structure upon interaction of OCN and OPN with $\mathrm{Ca}^{2+}, \mathrm{HPO}_{4}{ }^{-2}$, and $\beta$-GP (organic phosphate source) was studied at $37{ }^{\circ} \mathrm{C}$ (Figure 4). The secondary structures of proteins were analyzed by the Bestsel online tool (Table S4).

OCN formed $\alpha$-helices, anti-parallel $\beta$-sheets and turns. Upon addition of $\mathrm{Ca}^{2+}$, the helical and anti-parallel content increased and the turns decreased (Figure 4A and Table S4). Due to the presence of negatively charged residues, it is highly possible that $\mathrm{OCN}$ interacts with $\mathrm{Ca}^{2+}$, and this interaction increases helical and anti-parallel content. The interaction of $\mathrm{Ca}^{2+}$ and OCN has been proven in the previous studies. Hauschka et al. have shown that helix content of native chicken OCN was increased $30 \%$ and the helix content of decarboxylated chicken OCN was increased $8 \% .{ }^{60}$ The increase of helix content in our recombinant OCN was 3.4\%. This could be due to the lack of carboxylation. Although the effect of $\mathrm{Ca}^{2+}$ and other cations on the secondary structure of OCN was extensively studied, ${ }^{61,62}$ there is no information in the literature if OCN interacts with organic and inorganic phosphate and if the secondary structure of OCN is affected or not. In our study, upon the addition of $\beta$-GP, the secondary structure of the protein was largely conserved (Figure 4B and Table S4). Because the interaction of OCN with $\beta$-GP resulted in protection of the secondary structure, our data suggested that OCN interacted with $\beta$-GP without any conformational change or no interaction occurred. Michaelis-Menten kinetics experiments showed that OCN interacted with organic phosphate (Figure 3). So, the idea that OCN interacts with organic phosphate was supported by $\mathrm{CD}$ analysis. Upon the addition of $\mathrm{HPO}_{4}{ }^{-2}$, the helices were largely disrupted, and more anti-parallel $\beta$-sheets were formed (Figure $4 \mathrm{C}$ and Table S4). Therefore, the addition of inorganic phosphate ion $\left(\mathrm{P}_{\mathrm{i}}\right)$ changed the secondary structure of OCN.

OPN formed $\alpha$-helices, anti-parallel $\beta$-sheets and turns in addition to random coils. Upon addition of $\mathrm{Ca}^{2+}$, the secondary structure of OPN was largely conserved (Figure 4D and Table S4). The conservation of secondary structure implies that interaction of $\mathrm{Ca}^{2+}$ and OPN is not via compact domains but via flexible unstructured domains, which are mainly a D-rich HAP binding domain and ASARM peptide. ${ }^{63,64}$ Upon addition of $\beta$-GP, the secondary structure of the protein was slightly changed, but the anti-parallel $\beta$-sheet structures were still conserved (Figure $4 \mathrm{E}$ and Table S4). Because the interaction of OPN with $\beta$-GP resulted in the protection of the secondary structure, OPN interacts with $\beta$ GP without any conformational change, or no interaction occurs. Similar to OCN, OPN interacted with organic phosphate. These observations were supported by kinetic experiments (Figure 3). Upon addition of $\mathrm{HPO}_{4}{ }^{-2}$, the $\alpha$ helical and parallel $\beta$-sheet contents of the protein increased, while anti-parallel $\beta$-sheet content decreased (Figure 4F and Table S4). These changes may be due to an interaction that stabilizes the protein.

Gorski et al. ${ }^{27}$ has previously studied the secondary structure of rat OPN in the presence and absence of $\mathrm{Ca}^{2+}$. They have found that low concentrations of OPN showed random coil conformation, while high concentrations of OPN had helices, $\beta$-sheets, and turns $(29,24$, and $17 \%$, respectively). Other studies have shown that OPN was largely unstructured. Phosphorylation of serines in bone and milk OPN could be responsible for the increase in flexibility on the secondary structure. ${ }^{63,65}$ For instance, phosphorylation of serine at the LKFRISHEL sequence disrupt $\beta$-sheet structure. ${ }^{63}$ Absence of phosphorylation may be the reason why some compact structures were observed in our system.

Kazanecki et al. predicted two $\beta$-sheet regions in the secondary structure of OPN: SVVYGLR and LKFRISHEL. ${ }^{63}$ Positively charged residues in these regions $(\mathrm{K}, \mathrm{R}, \mathrm{H})$ may contribute to an increase in $\beta$-sheet content upon addition of $\mathrm{HPO}_{4}{ }^{-2}$. Positively charged residues are probably neutralized in the presence of $\mathrm{HPO}_{4}{ }^{-2}$, making these regions more compact and stabilize $\beta$-sheets.

Both OCN and OPN bind to $\beta$-GP without any significant conformational change, as the proteins affected ALP enzymatic activity through competitive binding (Figure 3 ). The helical structures in OCN were disrupted upon $\mathrm{HPO}_{4}{ }^{-2}$ binding; this may explain why $\mathrm{OCN}$ was less effective in increasing the reaction rate constant of ALP phosphatase activity compared to OPN. The formation of inorganic phosphate ions during phosphatase assay led to reduced binding of $\mathrm{OCN}$ to organic phosphate (Figure 3) due to the disruption in the secondary structure of OCN. 


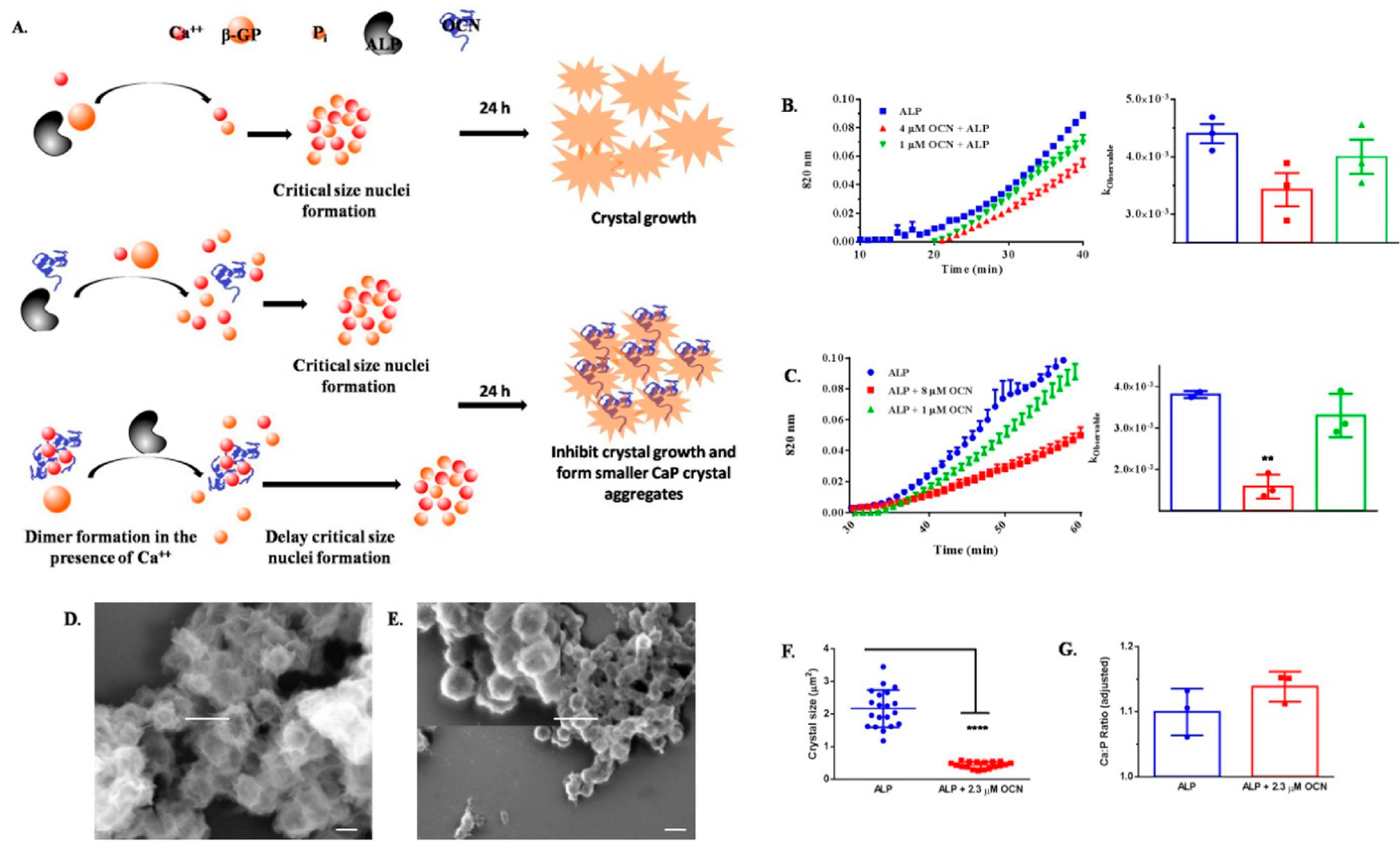

Figure 5. In vitrobiomineralization in the presence of ALP and OCN. (A) Schematic representation of the reaction with ALP in the absence of $\mathrm{OCN}$, and ALP was added to the reaction before or after $\mathrm{BB}\left(\mathrm{Ca}^{2+}\right.$ and $\left.\beta-\mathrm{GP}\right)$. (B) Initial mineral formation was detected by spectrophotometer when OCN and ALP were added into the reaction before $\mathrm{BB}\left(\mathrm{Ca}^{2+}\right.$ and $\beta$-GP). Initial mineral formation rate was calculated based on first 30 min of mineral formation in (B). (C) Initial mineral formation was detected by spectrophotometer when OCN and $\mathrm{BB}\left(\mathrm{Ca}^{2+}\right.$ and $\beta$-GP) were added into the reaction before ALP. Initial mineral formation rate was calculated based on the first 30 min of mineral formation in (C). (Error bars represents $N=3 \pm$ SEM.) The legends in (B) and (C) are also valid for the columns in $k_{\text {observable }}$ graphics, respectively. Statistical analysis was performed in Graphpad Prism software by one-way ANOVA. (D) SEM imaging of mineral formation in the presence of ALP after $24 \mathrm{~h}$ of incubation at $37^{\circ} \mathrm{C}$. (E) SEM imaging of mineral formation in the presence of ALP and OCN after $24 \mathrm{~h}$ of incubation at $37^{\circ} \mathrm{C}$. Scale bars in (D, E) represent $1 \mu \mathrm{m}$. (F) Crystal size is measured by the ImageJ program measure tool from SEM images from $N=20 \pm$ SEM and $N=18 \pm$ SEM crystals. Unpaired $t$ test was performed to analyze statistical significance. (G) Surface Ca:P ratio of the minerals formed in the presence of ALP and OCN after $24 \mathrm{~h}$ of incubation at $37^{\circ} \mathrm{C}$ detected by XPS. Three points with $400 \mu \mathrm{m}$ spot size were selected for scanning. Unpaired $t$ test was performed to analyze statistical significance. BB: $24 \mathrm{mM} \mathrm{CaCl}_{2}, 14.4 \mathrm{mM} \beta$-GP, $25 \mathrm{mM}$ Tris- $\mathrm{HCl}(\mathrm{pH}=7.4) \mathrm{ALP}(\leqslant 5 \mathrm{U}), 1 \mathrm{mM} \mathrm{MgCl} \mathrm{msed}_{2}$ for each reaction. All samples are in $25 \mathrm{mM}$ Tris- $\mathrm{HCl}, \mathrm{pH}=7.4$.

OCN and OPN Affect the Fate of Crystal Structures Differently in in Vitro Biomineralization. The effect of OCN and OPN on the formation of $\mathrm{CaP}$ crystals in vitro was characterized by spectrophotometer measurement, electron microscopy imaging, EDS, and XPS analysis. BB was prepared to provide a calcium and phosphate source for crystal formation. ALP unit enzyme concentration was determined to be $5 \mathrm{U}$ after several tests in order to find the concentration range that was high enough to see initial mineral formation within $1 \mathrm{~h}$ and low enough to differentiate the mineral formation rates of different groups (data not shown). $820 \mathrm{~nm}$ light scattering in the first $1 \mathrm{~h}$ for each reaction was recorded to monitor crystal formation, since it is known that $\mathrm{CaP}$ crystals scatter light at $820 \mathrm{~nm}^{56}$ The initialization of crystal formation was recorded, the differences between groups were differentiated, and $k_{\text {observable }}$ values were calculated from the slope of the linear regions of the scattering measurement curve in order to analyze the changes of initial mineral formation rates among groups.

First, the effect of $\mathrm{OCN}$ on the initial mineral formation rate was recorded. Surprisingly, the addition of ALP before or after the $\mathrm{BB}$ affected the results. When ALP was added before the
$\mathrm{BB}$, no difference was observed between the reaction rates of ALP and the different concentrations of OCN (Figure 5B). However, when ALP was added after the $\mathrm{BB}$, the reaction rate was significantly reduced upon increasing concentrations of OCN (Figure 5C). The biomineralization reaction starts when the two essential components are combined; ALP and the BB. ALP converts $\beta$-GP to $\mathrm{P}_{\mathrm{i}}$, and these inorganic phosphates interact with the $\mathrm{Ca}^{2+}$ ions in the solution to form initial $\mathrm{CaP}$ crystals. ${ }^{18}$ First, amorphous $\mathrm{CaP}$ aggregates are formed until $\mathrm{CaP}$ particles reach a critical size for nucleation. Once a critical size is reached, $\mathrm{CaP}$ particles start to grow up, and amorphous $\mathrm{CaP}$ aggregates are converted to more crystalline compounds. ${ }^{66}$ When the $\mathrm{BB}$ was added before ALP and OCN, OCN has time to interact with $\mathrm{Ca}^{2+}$ ions in the solution. The interaction of OCN with $\mathrm{Ca}^{2+}$ ions increased $\alpha$-helices and anti-parallel $\beta$-sheets (Figure $4 \mathrm{~A}$ and Table S4). Binding of OCN to $\mathrm{Ca}^{2+}$ not only decreased the number of free $\mathrm{Ca}^{2+}$ ions but also delayed formation of critical size nuclei and reduced the reaction rate (Figure $5 \mathrm{~A}-\mathrm{C}$ ). When the $\mathrm{BB}$ was added after ALP, $P_{i}$ ions started to form before the interaction of OCN with the $\mathrm{Ca}^{2+}$ ions because the $\mathrm{P}_{\mathrm{i}}$ ions disrupted the helical structure of OCN (Figure 4C), and the affinity of OCN 

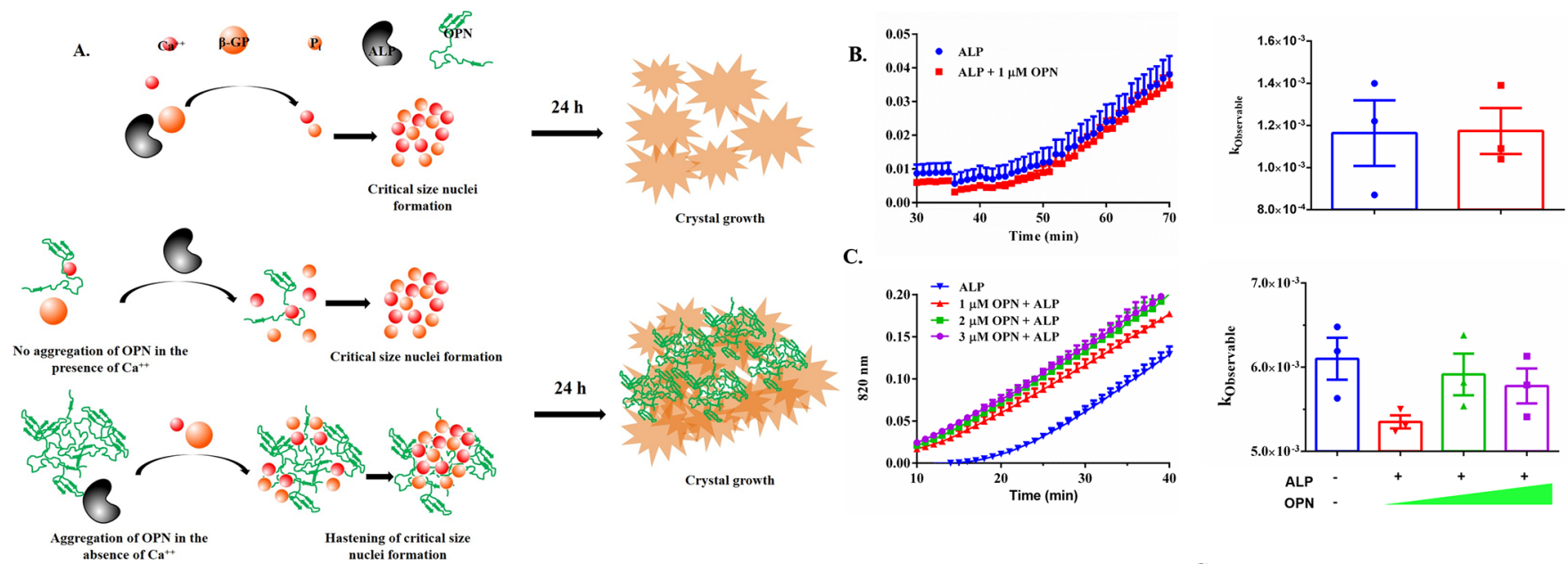

C.
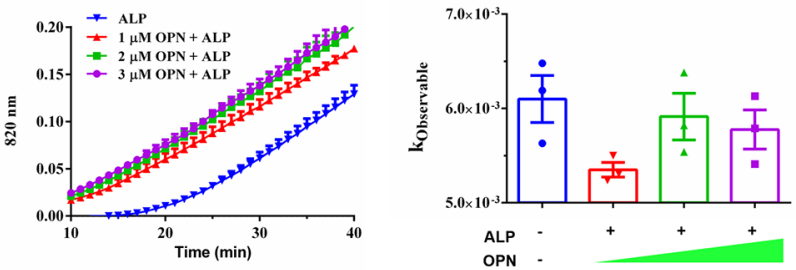

D.

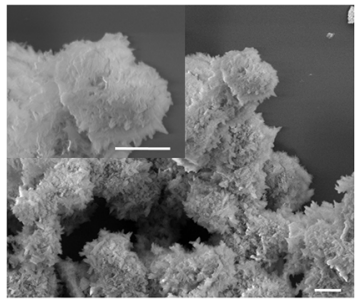

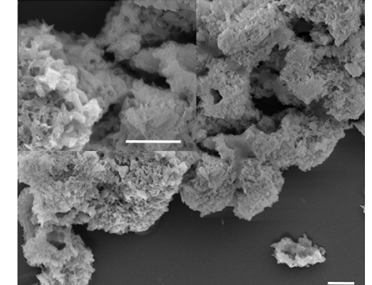

F.

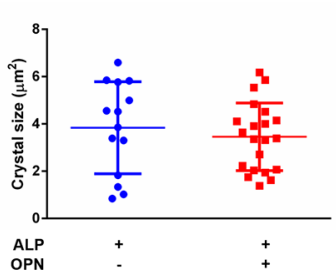

G.

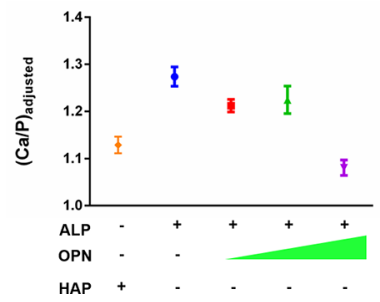

Figure 6. In vitro biomineralization in the presence of ALP and OPN. (A) Illustration of initial and late phases of CaP crystal formation in the presence of ALP only and both ALP and OPN. (B) Initial mineral formation was detected by spectrophotometer when BB and OPN were added into the reaction before ALP. Initial mineral formation rate was calculated based on first $30 \mathrm{~min}$ of mineral formation in (B). (C) Initial mineral formation detected by spectrophotometer when ALP and OPN were added into the reaction before BB. Initial mineral formation rate was calculated based on first 30 min of mineral formation in (C). (Error bars represents $N=3 \pm$ SEM.) The legends in (B and C) are also valid for the columns in $k_{\text {observable }}$ graphics, respectively. Statistical analysis was performed in Graphpad Prism software by one-way ANOVA. (D) SEM imaging of mineral formation in the presence of ALP after $24 \mathrm{~h}$ of incubation at $37^{\circ} \mathrm{C}$. (E) SEM imaging of mineral formation in the presence of ALP and 3 $\mu \mathrm{M}$ OPN after $24 \mathrm{~h}$ of incubation at $37^{\circ} \mathrm{C}$. Scale bars in (D-E) represent $1 \mu \mathrm{m}$. (F) Crystal size is measured by the ImageJ program measure tool from SEM images from $N=14 \pm$ SEM and $N=21 \pm$ SEM crystals. Unpaired $t$ test was performed to analyze statistical significance. (G) Surface Ca:P ratio of the minerals formed in the presence of ALP and OPN after $24 \mathrm{~h}$ of incubation at $37^{\circ} \mathrm{C}$ detected by XPS. Commercial HAP was used as a control. Three points with $400 \mu \mathrm{m}$ spot size are selected for scanning. One-way ANOVA was performed to analyze statistical significance of each sample compared to ALP. BB: $24 \mathrm{mM} \mathrm{CaCl}_{2}, 14.4 \mathrm{mM} \beta$-GP, $25 \mathrm{mM}$ Tris- $\mathrm{HCl}$ ( $\left.\mathrm{pH}=7.4\right)$, ALP ( $5 \mathrm{U}$ ), $1 \mathrm{mM} \mathrm{MgCl}_{2}$ used for each reaction. All samples are in $25 \mathrm{mM}$ Tris- $\mathrm{HCl}, \mathrm{pH}=7.4$.

to $\mathrm{Ca}^{2+}$ ions was lowered. Consequently, OCN cannot delay critical size nuclei formation, and the crystal formation reaction hastens (Figure 5A,B).

SEM imaging was performed to observe the effect of OCN on mineral shape. After $24 \mathrm{~h}$ of incubation at $37^{\circ} \mathrm{C}$, the crystal size decreased, and the crystals became more uniform compared to ALP only (Figure 5D,E). The decrease in crystal size was quantified by Image $J$ software by measuring the crystal area of 20 (ALP) and 18 (ALP and OCN) crystals. The average crystal size decreased from $2.17 \mu \mathrm{m}^{2}$ to $0.44 \mu \mathrm{m}^{2}$, and the SEM was decreased from 0.44 to 0.02 upon OCN addition to the reaction, indicating OCN not only caused a decrease in crystal size but also narrowed down the size distribution of crystals (Figure 5F). In order to analyze crystallinity of the minerals, the surface Ca:P ratio was calculated based on the XPS measurements. A higher Ca:P ratio is an indicator of a higher degree of crystallinity in $\mathrm{CaP}$ crystals. ${ }^{66}$ Although we expected an increase in the $\mathrm{Ca}: \mathrm{P}$ ratio of the minerals because the minerals are more ordered, there is no statistically significant increase in the Ca:P ratio (Figure 5G). This may be due to the measurement method. XPS only detects surface atoms. The surface minerals may be newly formed less crystalline forms, and the inner layers could still be more crystalline. ${ }^{67}$ Therefore, EDS analysis was performed to analyze crystallinity of the minerals (Figure S6). However, the difference cannot be observed. The inner layers are not more crystalline than the surface. So, it is depicted that OCN does affect crystal size, but not crystallinity during mineral formation. The decrease in crystal size could be due to inhibition of crystal growth on mineral surfaces.

OCN has 3 glutamic acid residues at positions 17, 21, and 24 , and these residues are found in the first $\alpha$-helical domain and regularly spaced (5.4 $\AA$ ), which is similar to the distance in HAP lattice. ${ }^{60,68}$ The correspondence of lattice structure with the glutamic acids in $\alpha$-helices provides binding of OCN to $\mathrm{HAP}$ and prevents further growth. Binding of OCN to crystal surfaces prevents binding of more $\mathrm{Ca}$ and $\mathrm{P}$ to mineral surfaces and inhibits crystal growth. Helical domains are thought to take part in crystal growth inhibition. ${ }^{22,69}$ Isbell et al. suggested that 2 equiv of $\mathrm{Ca}^{2+}$ is necessary for OCN to form an $\alpha$-helical structure and become a compact molecule, while it is less ordered and more extended in the absence of $\mathrm{Ca}^{2+}$. Addition of 3 more equiv of $\mathrm{Ca}^{2+}$ does not change the secondary structure, but makes the protein more stable. There is strong evidence that $\mathrm{OCN}$ undergoes dimerization upon binding to $\mathrm{Ca}^{2+}{ }^{20}$ The results obtained in this study are consistent with the previous work; inhibition of crystal growth by $\mathrm{OCN}$ was demonstrated via electron microscopy and crystal size analysis 
A
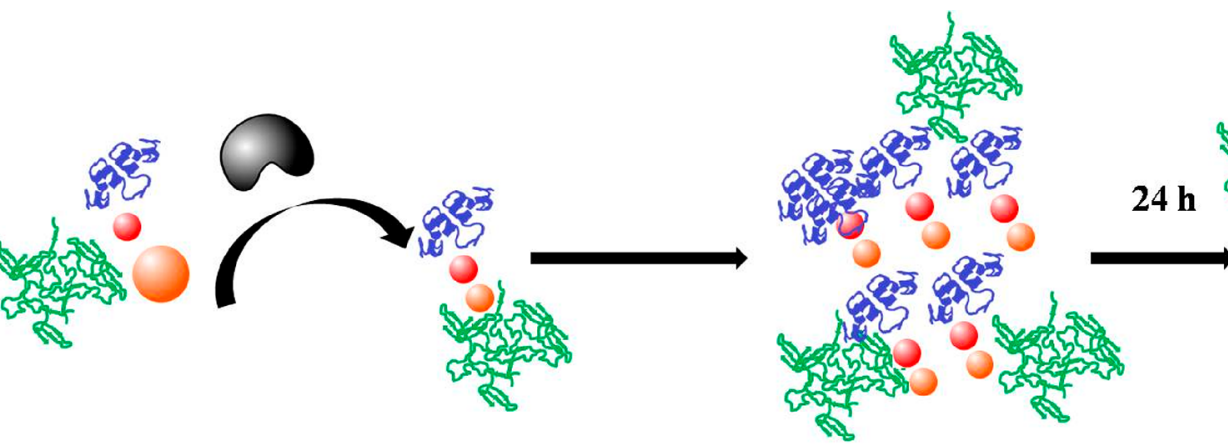

\begin{abstract}
Aggregation of $O P N$ and dimerization of $\mathrm{OCN}$
\end{abstract}

Delay critical size nuclei formation

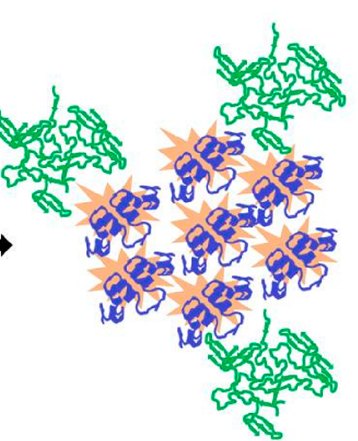

Inhibit crystal growth and form smaller CaP crystal aggregates, Ca/P ratio protected

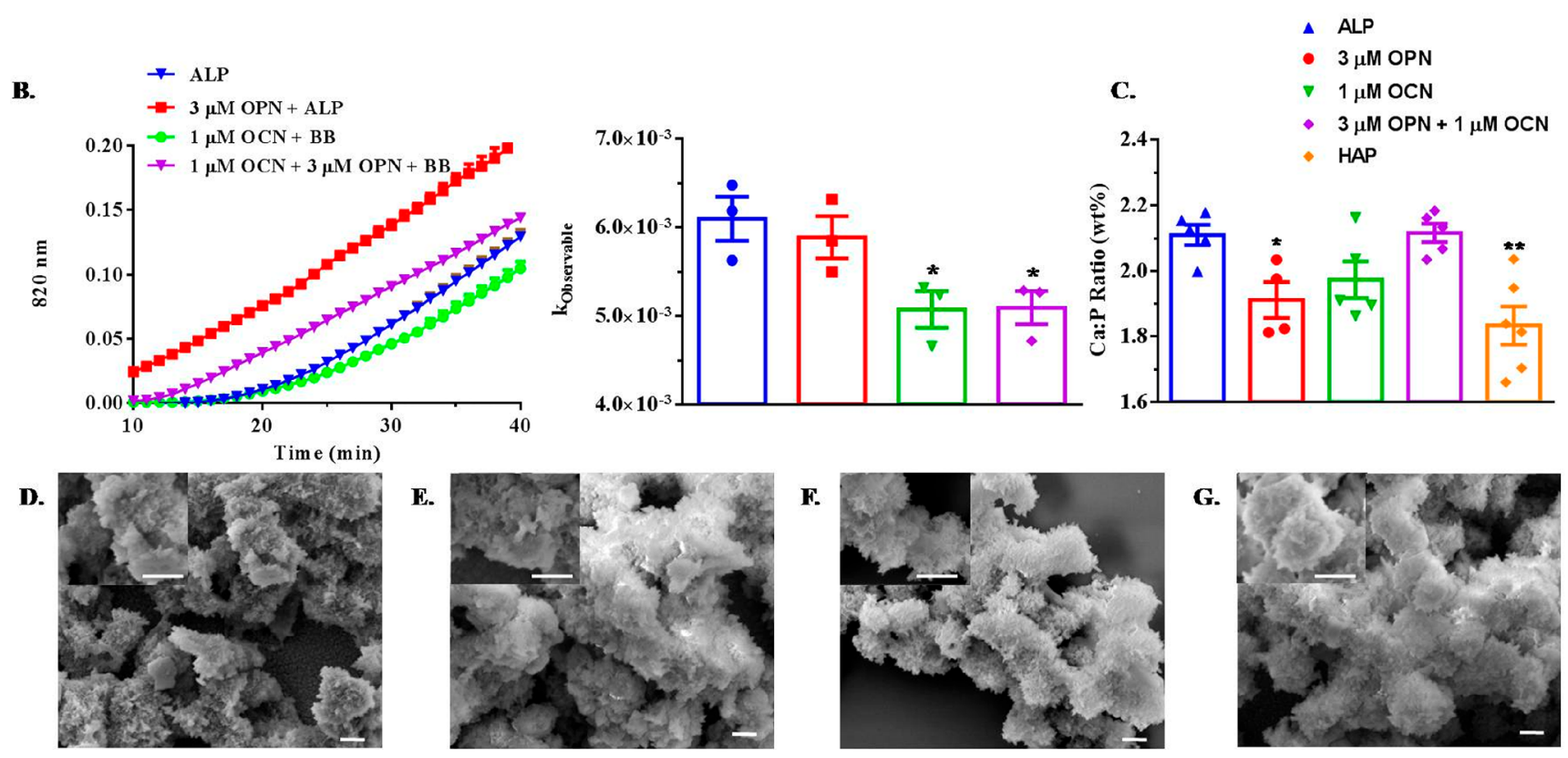

Figure 7. In vitro biomineralization in the presence of ALP and varying concentrations of OCN and OPN. (A) Illustration of initial and late phases of $\mathrm{CaP}$ crystal formation in the presence of ALP only and ALP, OCN, and OPN. (B) Initial mineral formation detected by spectrophotometer. Initial mineral formation rate calculated based on the first $40 \mathrm{~min}$ of mineral formation (one-way ANOVA) in (B). (C) $\mathrm{Ca} / \mathrm{P}$ ratio calculated by EDS analysis. (D-G) SEM imaging of mineral formation after $243 \mathrm{~h}$ of incubation at $37{ }^{\circ} \mathrm{C}$ in the presence of ALP only, ALP and $3 \mu \mathrm{M}$ OPN, ALP and $1 \mu \mathrm{M}$ OCN, and ALP, combination of $3 \mu \mathrm{M}$ OPN and $1 \mu \mathrm{M}$ OPN, respectively. Scale bars represent $1 \mu \mathrm{m} . \mathrm{BB}^{2} 24 \mathrm{mM} \mathrm{CaCl}, 14.4 \mathrm{mM}$ $\beta$-GP, $25 \mathrm{mM}$ Tris-HCl ( $\mathrm{pH}=7.4)$ ALP $(5 \mathrm{U}), 1 \mathrm{mM} \mathrm{MgCl}_{2}$ used for each reaction. All samples are in $25 \mathrm{mM} \mathrm{Tris}-\mathrm{HCl}, \mathrm{pH}=7.4$.

as well as disruption of critical size nuclei formation in the beginning (Figure 5). So, OCN both delays critical size nuclei formation in the initial phase of the reaction and inhibits crystal growth in late phase (Figure 5).

It should also be noted that the composition of mineralization reaction is constant in our system. So, while the crystallization proceeds, the $\mathrm{OH}^{-}$ions are incorporated into crystals leaving $\mathrm{H}^{+}$ions in solution, which makes the environment more acidic over time compared to the initial phase ( $\mathrm{pH} 7.4){ }^{70} \mathrm{H}^{+}$ions bind to negatively charged residues on OCN and OCN become more compact due to neutralization of the charges. ${ }^{71}$ When OCN becomes more compact, $\alpha$-helical content is promoted, although to a lesser extent compared to $\mathrm{Ca}^{2+}$ binding. ${ }^{71}$ The interaction of OCN and $\mathrm{H}^{+}$ions could help the inhibition of crystal growth by making OCN more helical and more prone to binding crystal lattices by releasing $\mathrm{H}^{+}$ions. ${ }^{71}$ Furthermore, positively charged arginine residues in $\mathrm{OCN}$ might be involved in interaction with
HAP crystals, since they can bind to phosphate ions in crystal structure. $^{60}$

Although some studies suggest that inhibition of crystal growth in the presence of OCN diminished upon decarboxylation, ${ }^{22}$ others support the idea that decarboxylation reduces the effect of OCN to inhibit crystal growth. ${ }^{60}$ Our results are consistent with the latter that crystal growth inhibition is possible with uncarboxylated recombinant OCN. The controversial results may be explained by the differences in experimental setups and measurement methods; most of the studies measure crystal growth but not crystallinity of the final minerals.

Then, the effect of OPN on the initial mineral formation rate was analyzed. The addition of ALP before or after the BB affected the results, as with OCN, but in a different manner. When $\mathrm{BB}$ added last to the reaction mixture, the reaction started earlier and occurred faster in the presence of OPN compared to ALP only condition. (Figure 6C). One possible explanation is OPN can interact with both $\mathrm{Ca}^{2+}$ and $\mathrm{P}_{\mathrm{i}}$ ions, 
but it has a higher affinity to $\mathrm{P}_{\mathrm{i}}$ ions. Because $\mathrm{P}_{\mathrm{i}}$ helps to conserve the compact structures of OPN (Figure 4F), OPN sequesters more $\mathrm{P}_{\mathrm{i}}$ ions, and this hastens the reaction. On the other hand, when ALP is added last to the reaction mixture, OPN first interacts with $\mathrm{Ca}^{2+}$ ions, not the $\mathrm{P}_{\mathrm{i}}$ ions. This interaction prevents OPN to be more compact when $P_{i}$ is formed after addition of ALP (Figure 4D). Upon the addition of ALP, $P_{i}$ formation starts, but $P_{i}$ can no longer interact with OPN or the affinity of OPN to $P_{i}$ was lowered (Figure $6 A, B$ ). Therefore, the reaction started later compared to the former case (Figure 6). Subsequently, the reaction rate was calculated from the slope of the reaction curve (first $30 \mathrm{~min}$ of linear region of scattering plot). Although the mineral formation started earlier when OPN and ALP was added into the reaction before $\mathrm{BB}$, there was no difference between the reaction rates of the groups (Figure 6B,C).

After $24 \mathrm{~h}$ of incubation at $37{ }^{\circ} \mathrm{C}$, SEM imaging was performed, and there was no observable difference between ALP only and ALP and OPN containing groups in terms of crystal size and shape (Figure 6D-F). The crystal size was quantified by Image $\mathrm{J}$ software by measuring the crystal area of 14 (ALP) and 21 (ALP and OPN) crystals. The average crystal size was $3.8 \mu \mathrm{m}^{2}$ and $3.4 \mu \mathrm{m}^{2}$, and the SEM was $0.52 \mu \mathrm{m}^{2}$ and $0.31 \mu \mathrm{m}^{2}$, respectively. Unpaired $t$ test analysis revealed no significant difference. Early and late phases of crystal formation are illustrated in Figure 6A.

Then, the surface Ca:P ratio was calculated based on the XPS measurements. The Ca:P ratio decreased when the OPN concentration increased to $3 \mu \mathrm{M}$ (Figure 6G, one-way ANOVA). This may be explained by the faster formation of $\mathrm{CaP}$ crystals, which results in less crystallinity at the surface or at all. In order to understand whether the change is at the surface or not, $\mathrm{Ca} / \mathrm{P}$ ratio was also investigated by $\mathrm{EDS}$ analysis, and the results were similar to XPS (Figure 7). Ca/P ratio was reduced in the presence of OPN, same as the XPS analysis.

Our results are consistent with the literature that unphosphorylated OPN does not inhibit mineralization reaction. ${ }^{65}$ Yet, it hastened mineralization in the presence of inorganic phosphate in our study. This could be due to the nucleator property of OPN, which was observed when OPN cross-linked to gap regions of collagen fibers via TG activity in bone tissue. ${ }^{34}$ Upon cross-linking, OPN forms aggregates which can induce a mineralization event. ${ }^{38}$ Promotion of nucleation was achieved in another study by using high concentrations of nonphosphorylated OPN peptide (NPP). This peptide is highly negatively charged containing 7 aspartic acid and 1 glutamic acid residues. Only high concentrations of this peptide promoted the nucleation event since it was prone to aggregation easily. This aggregation could be mimicking cross-linked aggregation of OPN. ${ }^{72}$ In our study, we observed nucleation of $\mathrm{CaP}$ crystals in the presence of OPN, which can be also mimicking the aggregation of OPN which was shown in previous research. ${ }^{34,67}$ Contrary to OCN, OPN has no effect on crystal size, suggesting it does not alter crystal growth (Figure 6F). The results are consistent with literature, where nonphosphorylated OPN has no effect on crystal growth inhibition. ${ }^{63,64,71-73}$

To observe the combined effects of OCN and OPN on biomineralization, a protein titration experiment was performed. The OPN concentration was increased when the OCN concentration was constant to see if the behavior of each protein changes in the presence of the other protein. Based on previous experiments, we hypothesized that the binding of calcium to OCN should decrease the crystal formation rate, yet the addition of $\mathrm{P}_{\mathrm{i}}$-bound OPN should increase the reaction rate. In the reaction setup, the $\mathrm{BB}$ contains both $\mathrm{Ca}^{2+}$ and $\beta$ $\mathrm{GP}$, and after being added to the buffer, proteins immediately interact with the ions. In the presence of $\mathrm{OCN}$, the reaction rate was decreased compared to ALP only (Figure $7 \mathrm{~B}$ ). In the presence of OPN, the reaction rate did not change, but the reaction started earlier (Figure $7 \mathrm{~B}$ ). When OCN and OPN were used together, the reaction started earlier compared to the ALP only condition, but later compared to OPN (Figure $7 \mathrm{~A}, \mathrm{~B})$. In addition, the reaction rate decreased compared to the ALP only condition. It means that OCN still delays crystal formation and OPN still hastens reaction (Figure 7A,B). The effects of two proteins can be used in a single reaction. After 24 $\mathrm{h}$, SEM imaging and EDS analysis were performed to observe the effect of proteins on late phases of mineral formation. $\mathrm{Ca} / \mathrm{P}$ ratio decreased in the presence of OPN, but the addition of OCN reversed the decrease in $\mathrm{Ca} / \mathrm{P}$ ratio (Figure $7 \mathrm{C}$ ).

Moreover, the surface $\mathrm{CaP}$ ratio of commercial HAP (Sigma) was calculated as a positive control. The crystallinity of biominerals formed in our in vitro system was higher than that of commercial HAP (Figures 6G and 7C, and Figure S6), and biominerals synthesized in this system can be a promising alternative for osteoblast differentiation and tissue regeneration (Figure 1).

\section{CONCLUSION}

Protein-protein and protein-small molecule interactions are crucial to understand the fundamentals of biomineralization. Extracellular matrix is also important to understand the fate of biomineralization and crystal formation, however a minimalist approach was taken in this work. To reduce the degree of complexity, we focused on two major biomineralization proteins OCN and OPN. An E. coli bacterial expression and purification system was constructed to study in vitro biomineralization and to produce HAP crystals in environmentally friendly and ambient conditions. This study is important in terms of developing innovative systems for HAP crystal synthesis by mimicking natural pathways. The interaction of OCN and OPN proteins with $\mathrm{Ca}^{2+}$ ions and organic and inorganic phosphate sources was studied to understand the effect of small molecules on the activity of these proteins. The interaction of OCN with $\mathrm{Ca}^{2+}$ ions makes it more stable, and it can exert its activity in a biomineralization reaction as nucleation delayer. Besides this, inorganic phosphate ions have the opposite effects on these proteins. While the OPN secondary structure is conserved, even it becomes more compact, the OCN secondary structure is disrupted upon binding to inorganic phosphate ions. The interaction of $\mathrm{OCN}$ with inorganic phosphate ions results in reduced nucleation delay activity, while the interaction of OPN with inorganic phosphate ions results in faster formation of initial $\mathrm{CaP}$ clusters. For organic phosphate sources, both proteins have no conformational changes, but they both can interact with organic phosphate and reduce the activity of the ALP enzyme by competitive binding. The logic behind these results should be further studied by calorimetric methods. Moreover, the in vitro biomineralization system was constructed to produce bone-type $\mathrm{CaP}$ crystals. While OCN reduces the reaction rate and crystal size, OPN promotes faster mineral formation and decreases the surface $\mathrm{CaP}$ ratio of the minerals. When the two proteins combined in a single reaction, 
both of them exerts their activity and becomes complementary to each other. The change in crystal morphology can change the differentiation capacity of as-formed $\mathrm{CaP}$ crystals. Outcomes of this study have a potential to serve in the engineering of innovative cellular pathways for OCN and OPN secretion at predefined concentrations to control the $\mathrm{CaP}$ crystals. This approach can yield in engineering implantable designer cells with genetic cellular devices for biomineralization to be used in regenerative medicine applications.

\section{ASSOCIATED CONTENT}

\section{S Supporting Information}

The Supporting Information is available free of charge on the ACS Publications website at DOI: 10.1021/acsbiomaterials.9b00649.

Nucleotide sequences of phoA, GST-OCN, OCN, and OPN genes, amino acid sequences of ALP, GST-OCN, OCN, and OPN proteins, nucleotide sequences of primers used in cloning ALP, OCN, and OPN genes, graphs for sequencing results of cloning, quantitative secondary structure analysis of OCN and OPN proteins and their changes upon addition of $\mathrm{CaCl}_{2}\left(\mathrm{Ca}^{2+}\right), \beta$-GP (organic phosphate, $\mathrm{P}$ ), and $\mathrm{Na}_{2} \mathrm{HPO}_{4}$ (inorganic phosphate, $\mathrm{P}_{\mathrm{i}}$ ), phosphatase assay showing overexpression of ALP in transformed cells, SDS-PAGE analysis of expression and purification of $\mathrm{OCN}, \mathrm{Ca} / \mathrm{P}$ ratio of the minerals formed in the presence of OCN calculated by EDS analysis (PDF)

\section{AUTHOR INFORMATION}

\section{Corresponding Author}

*E-mail: urartu@bilkent.edu.tr.

\section{ORCID}

Urartu Özgür Şafak Şeker: 0000-0002-5272-1876

\section{Author Contributions}

U.O.S.S. and E.D. conceived the study. E.D., E.S.K., E.Y., and R.E.A. carried out the gene cloning and protein expression. E.D. and E.Y. performed the biomineralization experiments. U.O.S.S. and E.D. analyzed the data and wrote the manuscript.

\section{Notes}

The authors declare no competing financial interest.

\section{ACKNOWLEDGMENTS}

U.O.S.S. is grateful to TUBA-GEBIP (Turkish Academy of Sciences Young Investigator Award) and for a Science Academy Award (BAGEP). E.D. is grateful for a TUBITAKBIDEB graduate scholarship. We thank Dr. Serkan Kasırga for his help with the EDS data.

\section{REFERENCES}

(1) Edwards, C. C.; Simmons, S. C.; Browner, B. D.; Weigel, M. C. Severe open tibial fractures. Results treating 202 injuries with external fixation. Clin. Orthop. Relat. Res. 1988, 230, 98-115.

(2) Jemal, A.; Siegel, R.; Ward, E.; Hao, Y.; Xu, J.; Murray, T.; Thun, M. J. Cancer statistics, 2008. Ca-Cancer J. Clin. 2008, 58 (2), 71-96.

(3) Riggs, B. L.; Melton, L. J. Involutional Osteoporosis. N. Engl. J. Med. 1986, 314 (26), 1676-1686.

(4) Trope, M. Regenerative potential of dental pulp. J. Endod 2008, 34, S13-S17.

(5) Greenwald, A. S.; Boden, S. D.; Goldberg, V. M.; Khan, Y.; Laurencin, C. T.; Rosier, R. N. Bone-graft substitutes: facts, fictions, and applications. J. Bone Joint Surg Am. 2001, 83, 98-103.
(6) Wittneben, J. G.; Buser, D.; Salvi, G. E.; Burgin, W.; Hicklin, S.; Bragger, U. Complication and failure rates with implant-supported fixed dental prostheses and single crowns: a 10-year retrospective study. Clin Implant Dent Relat Res. 2014, 16 (3), 356-64.

(7) Ai-Aql, Z. S.; Alagl, A. S.; Graves, D. T.; Gerstenfeld, L. C.; Einhorn, T. A. Molecular Mechanisms Controlling Bone Formation during Fracture Healing and Distraction Osteogenesis. J. Dent. Res. 2008, 87 (2), 107-118.

(8) Puzas, J. E.; Miller, M. D.; Rosier, R. N. Pathologic bone formation. Clin. Orthop. Relat. Res. 1989, 245, 269-281.

(9) Sadat-Shojai, M.; Khorasani, M. T.; Dinpanah-Khoshdargi, E.; Jamshidi, A. Synthesis methods for nanosized hydroxyapatite with diverse structures. Acta Biomater. 2013, 9 (8), 7591-621.

(10) Heise, U.; Osborn, J. F.; Duwe, F. Hydroxyapatite ceramic as a bone substitute. International Orthopaedics 1990, 14 (3), 329-338.

(11) Landi, E.; Celotti, G.; Logroscino, G.; Tampieri, A. Carbonated hydroxyapatite as bone substitute. J. Eur. Ceram. Soc. 2003, 23 (15), 2931-2937.

(12) Li, Z.; Yubao, L.; Aiping, Y.; Xuelin, P.; Xuejiang, W.; Xiang, Z. Preparation and in vitro investigation of chitosan/nano-hydroxyapatite composite used as bone substitute materials. J. Mater. Sci.: Mater. Med. 2005, 16 (3), 213-219.

(13) Teotia, A. K.; Raina, D. B.; Singh, C.; Sinha, N.; Isaksson, H.; Tägil, M.; Lidgren, L.; Kumar, A. Nano-Hydroxyapatite Bone Substitute Functionalized with Bone Active Molecules for Enhanced Cranial Bone Regeneration. ACS Appl. Mater. Interfaces 2017, 9 (8), 6816-6828.

(14) Kirkham, J.; Brookes, S. J.; Shore, R. C.; Wood, S. R.; Smith, D. A.; Zhang, J.; Chen, H.; Robinson, C. Physico-chemical properties of crystal surfaces in matrix-mineral interactions during mammalian biomineralisation. Curr. Opin. Colloid Interface Sci. 2002, 7 (1), 124132.

(15) Abbarin, N.; San Miguel, S.; Holcroft, J.; Iwasaki, K.; Ganss, B. The Enamel Protein Amelotin Is a Promoter of Hydroxyapatite Mineralization. J. Bone Miner. Res. 2015, 30 (5), 775-785.

(16) Tsao, Y.-T.; Huang, Y.-J.; Wu, H.-H.; Liu, Y.-A.; Liu, Y.-S.; Lee, K. O. Osteocalcin Mediates Biomineralization during Osteogenic Maturation in Human Mesenchymal Stromal Cells. Int. J. Mol. Sci. 2017, 18 (1), 159.

(17) Ibsen, C. J. S.; Gebauer, D.; Birkedal, H. Osteopontin Stabilizes Metastable States Prior to Nucleation during Apatite Formation. Chem. Mater. 2016, 28 (23), 8550-8555.

(18) Siller, A. F; Whyte, M. P Alkaline Phosphatase: Discovery and Naming of Our Favorite Enzyme. J. Bone Miner. Res. 2018, 33 (2), $362-364$.

(19) Gajjeraman, S.; Narayanan, K.; Hao, J. J.; Qin, C. L.; George, A. Matrix macromolecules in hard tissues control the nucleation and hierarchical assembly of hydroxyapatite. J. Biol. Chem. 2007, 282 (2), 1193-1204.

(20) D’Souza, R. N.; Cavender, A.; Sunavala, G.; Alvarez, J.; Ohshima, T.; Kulkarni, A. B.; MacDougall, M. Gene expression patterns of murine dentin matrix protein 1 (Dmp1) and dentin sialophosphoprotein (DSPP) suggest distinct developmental functions in vivo. J. Bone Miner. Res. 1997, 12 (12), 2040-9.

(21) O’Neill, E.; Awale, G.; Daneshmandi, L.; Umerah, O.; Lo, K. W. H. The roles of ions on bone regeneration. Drug Discovery Today 2018, 23 (4), 879-890.

(22) Romberg, R. W.; Werness, P. G.; Riggs, B. L.; Mann, K. G. Inhibition of hydroxyapatite-crystal growth by bone-specific and other calcium-binding proteins. Biochemistry 1986, 25 (5), 1176-1180.

(23) Yang, S.; He, H.; Wang, L.; Jia, X.; Feng, H. Oriented crystallization of hydroxyapatite by the biomimetic amelogenin nanospheres from self-assemblies of amphiphilic dendrons. Chem. Commun. 2011, 47 (36), 10100-10102.

(24) Wang, L.; Guan, X.; Du, C.; Moradian-Oldak, J.; Nancollas, G. H. Amelogenin Promotes the Formation of Elongated Apatite Microstructures in a Controlled Crystallization System. J. Phys. Chem. C 2007, 111 (17), 6398-6404. 
(25) Cai, Y.; Mei, D.; Jiang, T.; Yao, J. Synthesis of oriented hydroxyapatite crystals: Effect of reaction conditions in the presence or absence of silk sericin. Mater. Lett. 2010, 64 (24), 2676-2678.

(26) Kikuchi, M.; Ikoma, T.; Itoh, S.; Matsumoto, H. N.; Koyama, Y.; Takakuda, K.; Shinomiya, K.; Tanaka, J. Biomimetic synthesis of bone-like nanocomposites using the self-organization mechanism of hydroxyapatite and collagen. Compos. Sci. Technol. 2004, 64 (6), 819825.

(27) Gorski, J. P. Biomineralization of bone: a fresh view of the roles of non-collagenous proteins. Front. Biosci., Landmark Ed. 2011, 16, $2598-2621$.

(28) BOSKEY, A. L. Mineral-Matrix Interactions in Bone and Cartilage. Clin. Orthop. Relat. Res. 1992, 281, 244-274.

(29) Hauschka, P. V.; Lian, J. B.; Cole, D. E.; Gundberg, C. M. Osteocalcin and matrix Gla protein: vitamin K-dependent proteins in bone. Physiol. Rev. 1989, 69 (3), 990-1047.

(30) Sodek, J.; Ganss, B.; McKee, M. D. Osteopontin. Crit. Rev. Oral Biol. Med. 2000, 11 (3), 279-303.

(31) Hauschka, P. V.; Wians, F. H., Jr Osteocalcin-hydroxyapatite interaction in the extracellular organic matrix of bone. Anat. Rec. 1989, 224 (2), 180-188.

(32) Ducy, P.; Desbois, C.; Boyce, B.; Pinero, G.; Story, B.; Dunstan, C.; Smith, E.; Bonadio, J.; Goldstein, S.; Gundberg, C.; Bradley, A.; Karsenty, G. Increased bone formation in osteocalcin-deficient mice. Nature 1996, 382, 448.

(33) Denhardt, D. T.; Guo, X. Osteopontin: a protein with diverse functions. FASEB J. 1993, 7 (15), 1475-1482.

(34) Kaartinen, M. T.; Pirhonen, A.; Linnala-Kankkunen, A.; Mäenpää, P. H. Cross-linking of Osteopontin by Tissue Transglutaminase Increases Its Collagen Binding Properties. J. Biol. Chem. 1999, 274 (3), 1729-1735.

(35) Prince, C. W.; Oosawa, T.; Butler, W. T.; Tomana, M.; Bhown, A. S.; Bhown, M.; Schrohenloher, R. E. Isolation, characterization, and biosynthesis of a phosphorylated glycoprotein from rat bone. J. Biol. Chem. 1987, 262 (6), 2900-2907.

(36) Choi, J. H.; Keum, K. C.; Lee, S. Y. Production of recombinant proteins by high cell density culture of Escherichia coli. Chem. Eng. Sci. 2006, 61 (3), 876-885.

(37) Protein production and purification. Nat. Methods 2008, 5, 135-146 .

(38) Baneyx, F. Recombinant protein expression in Escherichia coli. Curr. Opin. Biotechnol. 1999, 10 (5), 411-421.

(39) Guan, K.; Dixon, J. E. Eukaryotic proteins expressed in Escherichia coli: An improved thrombin cleavage and purification procedure of fusion proteins with glutathione S-transferase. Anal. Biochem. 1991, 192 (2), 262-267.

(40) Sørensen, H. P.; Mortensen, K. K. Advanced genetic strategies for recombinant protein expression in Escherichia coli. J. Biotechnol. 2005, 115 (2), 113-128.

(41) Yun, Y. R.; Kim, H. W.; Kang, W.; Jeon, E.; Lee, S.; Lee, H. Y.; Kim, C. H.; Jang, J. H. Expression and purification recombinant human dentin sialoprotein in Escherichia coli and its effects on human dental pulp cells. Protein Expression Purif. 2012, 83 (1), 47-51.

(42) Svensson Bonde, J.; Bulow, L. One-Step Purification of Recombinant Human Amelogenin and Use of Amelogenin as a Fusion Partner. PLoS One 2012, 7 (3), No. e33269.

(43) Xiong, S. H.; Yu, L.; Tan, H. Y.; Huang, T.; Wang, C. Y.; Liu, D. Y.; Zhong, S. Z. Expression and purification of recombinant bone morphogenetic protein-2 in E.coli. Di Yi Jun Yi Da Xue Xue Bao 2002, 22 (5), 413-6.

(44) Smith, L. L.; Cheung, H. K.; Ling, L. E.; Chen, J.; Sheppard, D.; Pytela, R.; Giachelli, C. M. Osteopontin N-terminal domain contains a cryptic adhesive sequence recognized by alpha9betal integrin. J. Biol. Chem. 1996, 271 (45), 28485-91.

(45) Sampath, T. K.; Maliakal, J. C.; Hauschka, P. V.; Jones, W. K.; Sasak, H.; Tucker, R. F.; White, K. H.; Coughlin, J. E.; Tucker, M. M.; Pang, R. H. Recombinant human osteogenic protein-1 (hOP-1) induces new bone formation in vivo with a specific activity comparable with natural bovine osteogenic protein and stimulates osteoblast proliferation and differentiation in vitro. J. Biol. Chem. 1992, 267 (28), 20352-20362.

(46) Käkönen, S.-M.; Hellman, J.; Pettersson, K.; Lövgren, T.; Karp, M. Purification and Characterization of Recombinant Osteocalcin Fusion Protein Expressed inEscherichia coli. Protein Expression Purif. 1996, 8 (2), 137-144.

(47) Tartaix, P. H.; Doulaverakis, M.; George, A.; Fisher, L. W.; Butler, W. T.; Qin, C.; Salih, E.; Tan, M.; Fujimoto, Y.; Spevak, L.; Boskey, A. L. In Vitro Effects of Dentin Matrix Protein-1 on Hydroxyapatite Formation Provide Insights into in Vivo Functions. J. Biol. Chem. 2004, 279 (18), 18115-18120.

(48) He, G.; Dahl, T.; Veis, A.; George, A. Nucleation of apatite crystals in vitro by self-assembled dentin matrix protein 1 . Nat. Mater. 2003, 2 (8), 552-8.

(49) Lee, S. Y.; Kim, S. Y.; Park, S. H.; Kim, J. J.; Jang, J. H.; Kim, E. C. Effects of recombinant dentin sialoprotein in dental pulp cells. J. Dent. Res. 2012, 91 (4), 407-12.

(50) Polakowski, R.; Craig, D. B.; Skelley, A.; Dovichi, N. J. Single Molecules of Highly Purified Bacterial Alkaline Phosphatase Have Identical Activity. J. Am. Chem. Soc. 2000, 122 (20), 4853-4855.

(51) Mornet, E.; Stura, E.; Lia-Baldini, A.-S.; Stigbrand, T.; Ménez, A.; Le Du, M.-H. Structural Evidence for a Functional Role of Human Tissue Nonspecific Alkaline Phosphatase in Bone Mineralization. J. Biol. Chem. 2001, 276 (33), 31171-31178.

(52) O'Brie, P. J.; Herschlag, D. Functional interrelationships in the alkaline phosphatase superfamily: phosphodiesterase activity of Escherichia coli alkaline phosphatase. Biochemistry 2001, 40 (19), 5691-5699.

(53) Herries, D. G. Alkaline phosphatase: by R B McComb, G N Bowers, Jr and S Posen. pp 986. Plenum Press, New York and London. 1979. \$75 ISBN 0-306-40214-9. Biochem. Educ. 1981, 9 (2), 76 .

(54) Millán, J. L. Alkaline Phosphatases. Purinergic Signalling 2006, 2 (2), 335.

(55) Gibson, D. G.; Young, L.; Chuang, R.-Y.; Venter, J. C.; Hutchison, C. A., III; Smith, H. O. Enzymatic assembly of DNA molecules up to several hundred kilobases. Nat. Methods 2009, 6, 343.

(56) Gungormus, M.; Fong, H.; Kim, I. W.; Evans, J. S.; Tamerler, C.; Sarikaya, M. Regulation of in vitro Calcium Phosphate Mineralization by Combinatorially Selected Hydroxyapatite-Binding Peptides. Biomacromolecules 2008, 9 (3), 966-973.

(57) Lu, H. B.; Campbell, C. T.; Graham, D. J.; Ratner, B. D. Surface characterization of hydroxyapatite and related calcium phosphates by XPS and TOF-SIMS. Anal. Chem. 2000, 72 (13), 2886-94.

(58) Singh, P.; Sharma, L.; Kulothungan, S. R.; Adkar, B. V.; Prajapati, R. S.; Ali, P. S. S.; Krishnan, B.; Varadarajan, R. Effect of signal peptide on stability and folding of Escherichia coli thioredoxin. PLoS One 2013, 8 (5), e63442-e63442.

(59) Micsonai, A.; Wien, F.; Kernya, L.; Lee, Y.-H.; Goto, Y.; Réfrégiers, M.; Kardos, J. Accurate secondary structure prediction and fold recognition for circular dichroism spectroscopy. Proc. Natl. Acad. Sci. U. S. A. 2015, 112 (24), E3095-E3103.

(60) Hauschka, P. V.; Carr, S. A. Calcium-dependent.alpha.-helical structure in osteocalcin. Biochemistry 1982, 21 (10), 2538-2547.

(61) Dowd, T. L.; Rosen, J. F.; Mints, L.; Gundberg, C. M. The effect of $\mathrm{Pb} 2+$ on the structure and hydroxyapatite binding properties of osteocalcin. Biochim. Biophys. Acta, Mol. Basis Dis. 2001, 1535 (2), $153-163$.

(62) Wians, F. H.; Krech, K. E.; Hauschka, P. V. Effects of magnesium and calcium on osteocalcin adsorption to hydroxyapatite. Magnesium 1983, 2, 83-92.

(63) Kazanecki, C. C.; Uzwiak, D. J.; Denhardt, D. T. Control of osteopontin signaling and function by post-translational phosphorylation and protein folding. J. Cell. Biochem. 2007, 102 (4), 912-924.

(64) Hunter, G. K.; O’Young, J.; Grohe, B.; Karttunen, M.; Goldberg, H. A. The Flexible Polyelectrolyte Hypothesis of ProteinBiomineral Interaction. Langmuir 2010, 26 (24), 18639-18646.

(65) Gericke, A.; Qin, C.; Spevak, L.; Fujimoto, Y.; Butler, W. T.; Sørensen, E. S.; Boskey, A. L. Importance of Phosphorylation for 
Osteopontin Regulation of Biomineralization. Calcif. Tissue Int. 2005, 77 (1), 45-54.

(66) Birkedal, H., Phase Transformations in Calcium Phosphate Crystallization. In New Perspectives on Mineral Nucleation and Growth: From Solution Precursors to Solid Materials, Van Driessche, A. E. S., Kellermeier, M., Benning, L. G., Gebauer, D., Eds.: Springer International Publishing: Cham, 2017; pp 199-210.

(67) Wang, L.; Nancollas, G. H. Calcium Orthophosphates: Crystallization and Dissolution. Chem. Rev. 2008, 108 (11), 46284669.

(68) Cristiani, A.; Maset, F.; De Toni, L.; Guidolin, D.; Sabbadin, D.; Strapazzon, G.; Moro, S.; De Filippis, V.; Foresta, C. Carboxylation-dependent conformational changes of human osteocalcin. Front. Biosci., Landmark Ed. 2014, 19, 1105-1116.

(69) Hunter, G. K.; Hauschka, P. V.; Poole, R. A.; Rosenberg, L. C.; Goldberg, H. A. Nucleation and inhibition of hydroxyapatite formation by mineralized tissue proteins. Biochem. J. 1996, 317 (1), 59.

(70) Isbell, D. T.; Du, S.; Schroering, A. G.; Colombo, G.; Shelling, J. G. Metal ion binding to dog osteocalcin studied by $1 \mathrm{H}$ NMR spectroscopy. Biochemistry 1993, 32 (42), 11352-11362.

(71) Hunter, G. K. Role of Osteopontin in Modulation of Hydroxyapatite Formation. Calcif. Tissue Int. 2013, 93 (4), 348-354.

(72) Wang, L.; Guan, X.; Tang, R.; Hoyer, J. R.; Wierzbicki, A.; De Yoreo, J. J.; Nancollas, G. H. Phosphorylation of Osteopontin Is Required for Inhibition of Calcium Oxalate Crystallization. J. Phys. Chem. B 2008, 112 (30), 9151-9157.

(73) Ohri, R.; Tung, E.; Rajachar, R.; Giachelli, C. M. Mitigation of Ectopic Calcification in Osteopontin-Deficient Mice by Exogenous Osteopontin. Calcif. Tissue Int. 2005, 76 (4), 307-315. 